\title{
A Systematic Review of Predictive Modeling for Bronchiolitis
}

Gang Luo (corresponding author)

Department of Biomedical Informatics, University of Utah

Suite 140, 421 Wakara Way, Salt Lake City, UT 84108, USA

gang.luo@utah.edu

Phone: 1-801-213-3565

Flory L. Nkoy, Per H. Gesteland, Tiffany S. Glasgow, Bryan L. Stone

Department of Pediatrics, University of Utah

100 N Mario Capecchi Drive, Salt Lake City, UT 84113, USA

flory.nkoy@hsc.utah.edu, per.gesteland@hsc.utah.edu, tiffany.glasgow@hsc.utah.edu,bryan.stone@hsc.utah.edu

\begin{abstract}
Purpose: Bronchiolitis is the most common cause of illness leading to hospitalization in young children. At present, many bronchiolitis management decisions are made subjectively, leading to significant practice variation among hospitals and physicians caring for children with bronchiolitis. To standardize care for bronchiolitis, researchers have proposed various models to predict the disease course to help determine a proper management plan. This paper reviews the existing state of the art of predictive modeling for bronchiolitis. Predictive modeling for respiratory syncytial virus (RSV) infection is covered whenever appropriate, as RSV accounts for about $70 \%$ of bronchiolitis cases.

Methods: A systematic review was conducted through a PubMed search up to April 25, 2014. The literature on predictive modeling for bronchiolitis was retrieved using a comprehensive search query, which was developed through an iterative process. Search results were limited to human subjects, the English language, and children (birth-18 years).

Results: The literature search returned 2,312 references in total. After manual review, 168 of these references were determined to be relevant and are discussed in this paper. We identify several limitations and open problems in predictive modeling for bronchiolitis, and provide some preliminary thoughts on how to address them, with the hope to stimulate future research in this domain.
\end{abstract}

Conclusions: Many problems remain open in predictive modeling for bronchiolitis. Future studies will need to address them to achieve optimal predictive models.

Keywords: Bronchiolitis, predictive modeling, machine learning, respiratory syncytial virus 


\section{Introduction}

Bronchiolitis is inflammation of the smallest air passages in the lungs (bronchioles) and primarily a disease of children younger than two years. Bronchiolitis is the leading cause of and accounts for $16 \%$ of all infant hospitalizations [1-3]. 10\% of children are affected by bronchiolitis in their first year of life [4]. By age two, more than one third of children have experienced bronchiolitis [5]. In the U.S., bronchiolitis incurs an annual total hospitalization cost of \$543 million [6], and consumes significant emergency department (ED) and hospital resources. Bronchiolitis leads to approximately 238 outpatient visits, 71 hospitalizations, and 77 ED visits per 1,000 infant years [7]. About 30\% of infants with bronchiolitis evaluated in pediatric EDs are hospitalized [2]. Overall, about $10 \%$ of children with bronchiolitis are hospitalized [5]. Between $2 \%$ and $6 \%$ of all children with bronchiolitis require care in an intensive care unit (ICU) [8].

A variety of therapies, such as bronchodilators, are used in bronchiolitis with little supporting evidence [9], and minimal consensus on their use other than recommending that clinicians individualize care based on course and severity. Perhaps the only exception is the recommendation to use infection control procedures, but even the extent of this intervention is unclear beyond using hand decontamination.

In evaluating and treating bronchiolitis, a key step is an attempt to anticipate the disease course to guide the appropriate management setting and intensity [8]. At present, many bronchiolitis management decisions are made subjectively [2, 10]. This leads to significant practice variation, as is reflected in variable admission rates and use of specific therapies among different hospitals and physicians $[1,4,10-20]$. Observed practice variation is not explained by differences in patient severity and has little impact on outcomes, but has a significant impact on healthcare resource usage [17]. Excessive hospital admission leads to overuse of inpatient resources, exposes patients to unnecessary iatrogenic risks and other infectious diseases in the hospital, and unnecessarily exposes other hospitalized children to these patients' infectious respiratory pathogens $[12,18,21]$. One study [22] suggests that up to $10 \%$ of infants with bronchiolitis experience adverse events during their hospital stay. Alternatively, patients not properly admitted risk inadequate treatment and medical deterioration including death [12]. Thus, it is desirable to develop methodologies to standardize bronchiolitis care, which can help reduce healthcare cost and improve patient safety and outcome $[21,23,24]$.

One way to standardize care for bronchiolitis is to develop and use clinical practice guidelines [8, 9]. With proper implementation, clinical practice guidelines for bronchiolitis can reduce healthcare resource usage by up to $77 \%$ without negatively impacting clinical outcomes or patient family's satisfaction [23, 25-28]. However, due to an insufficient level of detail and limited amounts of evidence, existing clinical practice guidelines provide guidance for a limited number of patients 
and still rely heavily on individualized clinician judgment. More detailed guidelines are difficult to generalize because they cannot answer the many combinations of patient and illness characteristics, such as comorbidities.

Another way to standardize care for bronchiolitis is to develop predictive models [21, 29-37] and use them to help direct an optimal disease management plan. By using a data-driven approach to summarize useful information accumulated in clinical and administrative data sets, predictive models [38] can manage the level of individualized detail inherent in a clinical setting, complement clinical practice guidelines, and overcome their limitations. Predictive models are often integrated into computerized decision support tools [273]. These tools can support clinicians' provisional judgment, or lead clinicians to question and reconsider that judgment [31]. This is particularly useful for inexperienced junior physicians and physicians who see children relatively infrequently. In general, human experts usually make better decisions when they are provided with predictive models' computational results [39, page 6].

In this paper, we present an overview of existing predictive models for clinical management of bronchiolitis and disease outcomes as well as their limitations. We identify several knowledge gaps and opportunities for improving predictive modeling for bronchiolitis, which can help direct the proper care setting and management for children with bronchiolitis. We discuss how to use machine learning techniques to address some of the gaps and limitations, and hope this paper can stimulate future research on predictive modeling for bronchiolitis. Our paper also covers predictive modeling for respiratory syncytial virus (RSV) infection whenever appropriate, as RSV accounts for about 70\% of bronchiolitis cases [40] and has a richer predictive modeling literature base. A list of acronyms used in this paper is provided in the appendix.

\section{Methods}

The methodology of our study follows the principles of the Preferred Reporting Items for Systematic Reviews and MetaAnalyses guideline [272]. The study protocol was designed by and iteratively refined with inputs from all study co-authors.

We conducted a systematic review limited to PubMed by developing a search strategy to retrieve the literature on predictive modeling for bronchiolitis through April 25, 2014. We started from an initial straightforward search query: (bronchiolitis or RSV) AND prediction. For each retrieved reference, two independent reviewers (GL and BS) evaluated the title and abstract to determine potential relevancy. Relevancy was judged based on pre-defined inclusion criteria ensuring that the article's primary focus addressed predictive modeling for some aspect of the clinical management of bronchiolitis/RSV infection and/or disease outcomes. We included articles describing predictors of or risk factors for outcomes regardless of their levels of scientific evidence, in an effort to investigate as many predictors and risk factors as possible to include all factors that might increase the accuracy of machine learning predictive models. If a reference appeared to be potentially relevant, the full text was evaluated 
to make a final inclusion decision. We also reviewed the citations in the included articles. If a citation was found to be relevant and missing from the original search results, a keyword phrase was extracted from this citation and added to the search query for expansion to include the relevant citation and other similar articles.

This process was repeated iteratively until a comprehensive search query was developed. Many keyword phrases added to the search query were forms of or synonyms of the words prediction and RSV. We also found that we could use specific keyword phrases to exclude irrelevant articles and narrow our search results. The final search query used was (bronchiolitis or RSV or "respiratory syncytial virus” or "respiratory syncytial viral”) AND (predict OR predicting OR predicts or predicted OR prediction OR predictive OR predictor OR predictors OR “risk scoring” OR “risk factor” OR “risk factors” OR asthma OR epidemiologic* OR management OR update) NOT (bronchiectasis OR malignancy OR “bronchiolitis obliterans” OR transplant). Search results were limited to human subjects, the English language, and children (birth-18 years). The final literature review included articles meeting the pre-defined inclusion criteria. Disagreements about inclusion of individual articles were addressed by discussion among GL and BS, and if needed a third reviewer (FN). One reviewer (GL) extracted from the included articles information on five dimensions: purpose for making the prediction, patient population, methods used for building predictive models, risk factors and/or predictors identified, and performance of the predictive models. Any issues involving uncertainty were resolved through discussion among GL and BS, and if needed a third reviewer (FN).

\section{Results}

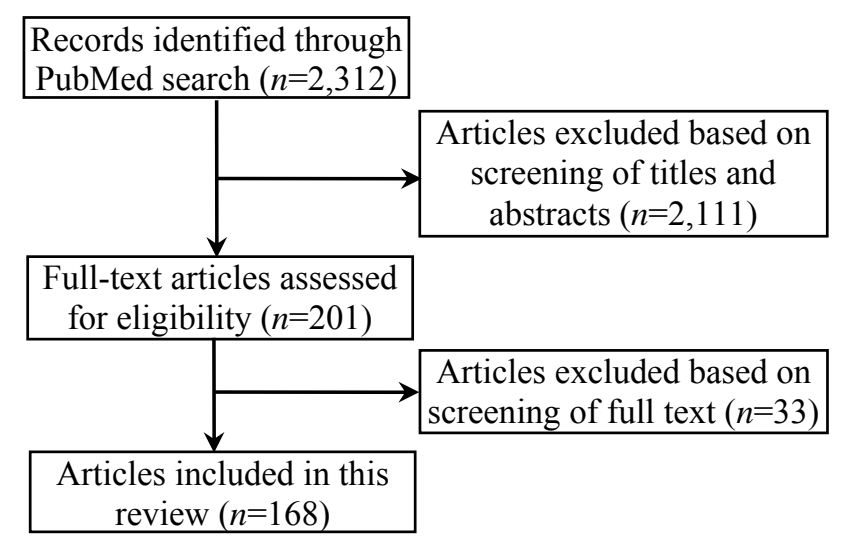

Fig. 1 Flowchart of the article selection process.

As shown in Fig. 1, the literature search returned 2,312 references in total. 201 appeared to be potentially relevant after review of titles and abstracts, and underwent full-text review. 168 of these were determined to be relevant and are discussed in this paper. The included articles are primarily predictive modeling studies and observational cohort studies regarding identifying predictors and risk factors, and contain only two systematic reviews and one randomized controlled trial illustrating 
the gap in high-quality evidence addressing this subject. In this section, we describe the state of the art of the predictive modeling areas of clinical interest for bronchiolitis, and identify open problems in predictive modeling for bronchiolitis. A summary of the primary clinical research topics on predictive modeling for bronchiolitis is provided in Table 1. Our categorization of these topics is based on input from study co-authors who are domain experts in pediatrics (FN, PG, TG, and BS) and articulated the major problems regarding bronchiolitis management in multiple iterations.

Table 1. Categorization and current status of the primary clinical research topics on predictive modeling for bronchiolitis.

\begin{tabular}{|c|c|c|c|c|}
\hline $\begin{array}{l}\text { Primary } \\
\text { category }\end{array}$ & Sub-category & $\begin{array}{c}\text { Methods for } \\
\text { building existing } \\
\text { predictive models }\end{array}$ & $\begin{array}{c}\text { Predictors } \\
\text { and/or } \\
\text { risk } \\
\text { factors } \\
\text { identified? }\end{array}$ & Open problems \\
\hline \multirow{5}{*}{$\begin{array}{l}\text { Predict optimal } \\
\text { escalation and } \\
\text { de-escalation of } \\
\text { care setting for } \\
\text { bronchiolitis } \\
\text { patients }\end{array}$} & $\begin{array}{l}\text { Predict hospital } \\
\text { admission from the } \\
\text { ED }\end{array}$ & \begin{tabular}{|l|} 
Logistic regression, \\
neural network \\
ensemble, scoring \\
system, CART \\
\end{tabular} & Yes & $\begin{array}{l}\text { Predict the true need for hospital admission for } \\
\text { bronchiolitis patients in the ED. }\end{array}$ \\
\hline & \begin{tabular}{|l|} 
Predict hospital \\
admission in the ED \\
observation unit
\end{tabular} & None & Yes & $\begin{array}{l}\text { Predict immediately before observation unit } \\
\text { admission, whether a bronchiolitis patient will } \\
\text { eventually have a true need for hospital } \\
\text { admission. }\end{array}$ \\
\hline & $\begin{array}{l}\text { Predict ICU } \\
\text { admission }\end{array}$ & $\begin{array}{l}\text { Logistic regression, } \\
\text { applying a threshold } \\
\text { to a single clinical } \\
\text { parameter }\end{array}$ & Yes & $\begin{array}{l}\text { (1) Predict with high accuracy ICU transfer need } \\
\text { for a patient admitted to the general inpatient } \\
\text { ward with bronchiolitis (or RSV infection). } \\
\text { (2) Predict the true need for ICU admission for } \\
\text { bronchiolitis patients in the ED. }\end{array}$ \\
\hline & $\begin{array}{l}\text { Predict optimal } \\
\text { disposition in the } \\
\text { primary care setting }\end{array}$ & None & Yes & $\begin{array}{l}\text { Predict in the primary care setting, whether a } \\
\text { bronchiolitis patient will use acute care for } \\
\text { bronchiolitis in the near future. }\end{array}$ \\
\hline & $\begin{array}{l}\text { Predict safe } \\
\text { discharge and } \\
\text { unscheduled visit }\end{array}$ & Logistic regression & No & $\begin{array}{l}\text { Predict upon ED discharge, whether a } \\
\text { bronchiolitis patient will have an unscheduled } \\
\text { visit in the very near future. }\end{array}$ \\
\hline \multirow{5}{*}{$\begin{array}{l}\text { Make } \\
\text { predictions } \\
\text { related to } \\
\text { respiratory } \\
\text { support }\end{array}$} & $\begin{array}{l}\text { Predict whether a } \\
\text { bronchiolitis patient } \\
\text { will develop apnea } \\
\end{array}$ & Risk criteria & Yes & $\begin{array}{l}\text { Predict with high accuracy whether a } \\
\text { bronchiolitis patient in the ED, general inpatient } \\
\text { ward, or ICU will develop apnea. }\end{array}$ \\
\hline & $\begin{array}{l}\text { Predict the use of a } \\
\text { specific type of } \\
\text { NIPPV }\end{array}$ & None & Yes & $\begin{array}{l}\text { Predict whether a bronchiolitis patient in the ED } \\
\text { or general inpatient ward will eventually use a } \\
\text { specific type of NIPPV. }\end{array}$ \\
\hline & $\begin{array}{l}\text { Predict NIPPV } \\
\text { failure }\end{array}$ & None & Yes & $\begin{array}{l}\text { Predict whether a bronchiolitis patient in the } \\
\text { hospital requiring positive pressure ventilation } \\
\text { support will fail NIPPV. }\end{array}$ \\
\hline & $\begin{array}{l}\text { Predict the use of } \\
\text { supplemental oxygen }\end{array}$ & $\begin{array}{l}\text { Bronchiolitis } \\
\text { severity score }\end{array}$ & Yes & $\begin{array}{l}\text { (1) Predict with high accuracy whether a } \\
\text { bronchiolitis patient in the ED or inpatient ward } \\
\text { will eventually use supplemental oxygen. } \\
\text { (2) Predict the number of days for which a } \\
\text { bronchiolitis patient in the ED or inpatient ward } \\
\text { will use supplemental oxygen. }\end{array}$ \\
\hline & $\begin{array}{l}\text { Predict the use of } \\
\text { mechanical } \\
\text { ventilation }\end{array}$ & Logistic regression & Yes & $\begin{array}{l}\text { Predict with high accuracy the need of } \\
\text { mechanical ventilation in bronchiolitis patients. }\end{array}$ \\
\hline
\end{tabular}




\begin{tabular}{|c|c|c|c|c|}
\hline & $\begin{array}{l}\text { Predict prolonged } \\
\text { mechanical } \\
\text { ventilation }\end{array}$ & Logistic regression & Yes & $\begin{array}{l}\text { Predict prolonged mechanical ventilation on a } \\
\text { patient who is admitted to the ICU with } \\
\text { bronchiolitis and requires mechanical ventilation. }\end{array}$ \\
\hline & $\begin{array}{l}\text { Predict the use of } \\
\text { extracorporeal } \\
\text { membrane } \\
\text { oxygenation }\end{array}$ & None & Yes & $\begin{array}{l}\text { Predict whether a patient hospitalized with RSV } \\
\text { bronchiolitis will need extracorporeal membrane } \\
\text { oxygenation support. }\end{array}$ \\
\hline & $\begin{array}{l}\text { Predict extubation } \\
\text { failure }\end{array}$ & None & Yes & $\begin{array}{l}\text { Predict extubation failure in bronchiolitis patients } \\
\text { in the ICU for all ventilation modes. }\end{array}$ \\
\hline \multirow{3}{*}{$\begin{array}{l}\text { Make } \\
\text { predictions } \\
\text { about the value } \\
\text { of tests and other } \\
\text { evaluations on a } \\
\text { bronchiolitis } \\
\text { patient }\end{array}$} & $\begin{array}{l}\text { Predict serious } \\
\text { bacterial infection }\end{array}$ & None & Yes & $\begin{array}{l}\text { Predict serious bacterial infection for patients } \\
\text { hospitalized with bronchiolitis. }\end{array}$ \\
\hline & $\begin{array}{l}\text { Predict an unhelpful } \\
\text { chest X-ray }\end{array}$ & Logistic regression & No & $\begin{array}{l}\text { Predict an unhelpful chest X-ray for bronchiolitis } \\
\text { patients. }\end{array}$ \\
\hline & $\begin{array}{l}\text { Identify RSV } \\
\text { infection }\end{array}$ & Logistic regression & Yes & $\begin{array}{l}\text { Accurately identify RSV infection and provide } \\
\text { reliable prediction for all patient populations } \\
\text { suspected of having RSV infection. }\end{array}$ \\
\hline \multirow{2}{*}{$\begin{array}{l}\text { Make } \\
\text { predictions } \\
\text { regarding the } \\
\text { current } \\
\text { hospitalization }\end{array}$} & $\begin{array}{l}\text { Predict hospital } \\
\text { length of stay }\end{array}$ & $\begin{array}{l}\text { Logistic regression, } \\
\text { CART, neural } \\
\text { network ensemble }\end{array}$ & Yes & $\begin{array}{l}\text { Predict with high accuracy hospital length of stay } \\
\text { of a bronchiolitis patient. }\end{array}$ \\
\hline & $\begin{array}{l}\text { Predict } \\
\text { hospitalization cost }\end{array}$ & Linear regression & Yes & $\begin{array}{l}\text { Predict with high accuracy hospitalization cost of } \\
\text { a patient to be admitted for bronchiolitis. }\end{array}$ \\
\hline \multirow{3}{*}{$\begin{array}{l}\text { Make } \\
\text { predictions } \\
\text { related to the use } \\
\text { of palivizumab }\end{array}$} & $\begin{array}{l}\text { Predict RSV } \\
\text { hospitalization }\end{array}$ & $\begin{array}{l}\text { Logistic regression, } \\
\text { discriminatory } \\
\text { function analysis }\end{array}$ & Yes & $\begin{array}{l}\text { Predict the true need for seasonal RSV (or } \\
\text { bronchiolitis) hospitalization for all young } \\
\text { children. }\end{array}$ \\
\hline & $\begin{array}{l}\text { Predict compliance } \\
\text { with palivizumab }\end{array}$ & None & Yes & Predict compliance with palivizumab. \\
\hline & $\begin{array}{l}\text { Predict community } \\
\text { RSV activity }\end{array}$ & $\begin{array}{l}\text { Naive Bayes, } \\
\text { autoregressive } \\
\text { integrated moving } \\
\text { average }\end{array}$ & Yes & $\begin{array}{l}\text { Predict community RSV activity with high } \\
\text { accuracy. }\end{array}$ \\
\hline \multicolumn{2}{|c|}{$\begin{array}{l}\text { Predict whether a bronchiolitis } \\
\text { patient will later be diagnosed with } \\
\text { asthma }\end{array}$} & Logistic regression & Yes & $\begin{array}{l}\text { Predict with high accuracy whether a } \\
\text { bronchiolitis patient will later be diagnosed with } \\
\text { asthma. }\end{array}$ \\
\hline
\end{tabular}

As explained in Sections 3.9 and 3.10 in detail, almost every existing predictive model for bronchiolitis was developed for a subset of bronchiolitis patients rather than for all bronchiolitis patients. In addition, most of the existing predictive models for bronchiolitis have inadequate accuracy. Moreover, many previous studies only identified various predictors or risk factors for managing bronchiolitis, but did not develop any predictive model for bronchiolitis.

\subsection{Predicting optimal escalation and de-escalation of care setting for bronchiolitis patients}

\subsubsection{Predicting hospital admission from the ED}

Much existing work on predictive modeling for bronchiolitis is related to predicting hospital admission in the ED setting.

Walsh et al. [36] used neural network ensemble to predict whether a bronchiolitis patient in the ED will be admitted or discharged, with an accuracy of $81 \%$. In comparison, the admitting resident physicians made correct decisions $77 \%$ of the time, using an attending pediatrician's judgment and a length of stay longer than one day as the comparator gold standard. 
Marlais et al. [31] used a scoring system to predict whether a bronchiolitis patient in the ED will be admitted, with an Area Under the receiver operating characteristic Curve (AUC) of $81 \%$. This study included only children no more than one year old. Destino et al. [41] used the Children's Hospital of Wisconsin Respiratory Score to make the same prediction, with a low sensitivity of $65 \%$, a low specificity of $65 \%$, and a low AUC of $68 \%$.

Using nasal wash lactate dehydrogenase concentration level, Laham et al. [42] built a logistic regression model to predict whether a bronchiolitis patient in the ED will be admitted. The predictive model achieved an AUC of $87 \%$, a classification accuracy of $80 \%$, a sensitivity of $81 \%$, a specificity of $77 \%$, a positive predictive value of $88 \%$, and a negative predictive value of $66 \%$.

Corneli et al. [43] used Classification And Regression Tree (CART) to predict whether an infant with bronchiolitis in the ED will be admitted, with a low sensitivity of $56 \%$ and a specificity of $74 \%$. This study used various criteria to exclude most infants with bronchiolitis in the ED.

For bronchiolitis patients in the ED, Walsh et al. [24] built a logistic regression model to predict the need for hospital admission, which was defined as actual hospital admission, discharge with a subsequent return visit requiring an admission, or clearly inappropriate discharge. This definition does not reflect a true need for admission because some admissions are unnecessary [21]. The developed model achieved a sensitivity of $91 \%$, a specificity of $83 \%$, and a low positive predictive value of $62 \%$.

In addition to the articles constructing predictive models, there are some other articles describing predictors. For bronchiolitis patients in the ED, Al-Shehri et al. [44-48] identified several predictors of hospital admission: prematurity, chronic lung disease (primarily bronchopulmonary dysplasia), atopic dermatitis, pure formula feeding (no breast feeding), passive smoking, age $\leq$ one year, nasopharyngeal lactate dehydrogenase value, low dew point, enterovirus infection, absence of familial atopy, rhinovirus, and co-infection. Voets et al. [35] identified three predictors of hospital and ICU admission: age < six months, respiratory rate $>45$ breaths per minute, and oxygen saturation $<95 \%$ at sea level. This study excluded patients with chronic lung disease, prematurity, underlying cardiac disease, or neurological diseases.

For previously healthy infants with RSV infection, Somech et al. [49] identified several predictors of hospital admission: fever, $\mathrm{SaO}_{2}$ level, abnormal chest auscultation findings, abnormal chest X-ray, and the clinical severity score suggested by Wang et al. [50]. Parker et al. [2] identified several predictors of major medical interventions in bronchiolitis patients, including oxygen administration for $\geq 30$ minutes for saturation $<90 \%$ in room air, intravenous fluid bolus of $\geq 20 \mathrm{ml} / \mathrm{kg}$, any treatment 
for apnea, and ICU admission. This study excluded infants with bronchiolitis who were previously unhealthy and provided no predictive model.

Some hospital admissions are unnecessary [21], and some ED discharges to home should have been admitted. It is important to identify the true need for hospital admission rather than only the occurrence of hospital admission. Although some of the work mentioned above achieved reasonably good prediction accuracies, none of the work mentioned above has predicted the true need for hospital admission for bronchiolitis patients in the ED. This remains an open problem. A true need for hospital admission is defined as ED discharge with a return visit for bronchiolitis within 12 hours, which results in hospital admission requiring supportive interventions for at least 12 hours. The choice of the first 12 hours is somewhat arbitrary, but is believed to have clinical face validity for representing the same episode of bronchiolitis and reflect premature discharge. A true need for hospital admission is also reflected by inpatient admission requiring the use of any of the major medical interventions for at least 12 hours for bronchiolitis patients in the hospital, including oxygen administration, intravenous fluid administration, suctioning for airway clearance, cardiovascular support, invasive positive pressure ventilation (mechanical ventilation), noninvasive positive pressure ventilation (NIPPV), chest physiotherapy, inhaled therapy (bronchodilator and mucolytics), and nutritional support (enteral feeding and total parenteral nutrition). Continuous positive airway pressure (CPAP), high-flow nasal cannula (HFNC) oxygen therapy, and bilevel positive airway pressure (BiPAP) are three examples of NIPPV.

\subsubsection{Predicting hospital admission in the ED observation unit}

About $36 \%$ of EDs in the U.S. have observation units treating patients for up to 24 hours [51]. The observation unit is used to avoid unnecessary or inefficient hospital admissions [52]. It offers treatments within defined areas for a period longer than the usual ED visit but shorter than a full inpatient hospital admission [52]. 55\% of bronchiolitis patients in the observation unit fail discharge within 24 hours and are subsequently hospitalized [53]. Unexpected hospitalization from the observation unit involves transfer of care, and thus can decrease the efficiency and safety of both patient care and the observation unit itself [52].

At present, limited information exists on how to best select patients suitable for care in the observation unit [52]. For bronchiolitis patients in the observation unit, Yusuf et al. [54] identified several predictors of hospital admission: parental report of poor feeding or increased work of breathing, oxygen saturation $<93 \%$ at sea level, and ED treatment with racemic epinephrine and intravenous fluids. For all patients (not limited to bronchiolitis patients) in the observation unit, Alpern et al. [52] identified several predictors of hospital admission. 
It remains an open problem to develop models to predict immediately before observation unit admission, whether a bronchiolitis patient will eventually have a true need for hospital admission. If one can predict that a bronchiolitis patient will have such a need, admission can be directed to the hospital rather than to the observation unit.

\subsubsection{Predicting ICU admission}

By applying a threshold to a single clinical parameter, Brooks et al. [55] built a model to predict whether an infant admitted to the general pediatric ward with RSV infection will be transferred to the ICU. In theory, this capability could support development of alternative care strategies, such as early use of NIPPV, for treating infants with RSV infection who present initially with milder symptoms. This study used previously healthy, full-term infants rather than all infants admitted with RSV infection. The developed model had a poor sensitivity below $30 \%$, which is too low for identifying the majority of infants at risk. It remains an open problem to predict with high accuracy ICU transfer need for a patient admitted to the general inpatient ward with bronchiolitis (or RSV infection).

For children with bronchiolitis in the ED, Damore et al. [29] identified several predictors of ICU admission and built a logistic regression model to predict ICU admission, with an AUC of $80 \%$. This study excluded bronchiolitis patients with previous ED visits. It used a small sample size of 50 ICU patients and hence could not assess less common risk factors.

For infants with RSV bronchiolitis, Mandelberg et al. [56] found peripheral blood mononuclear cell proliferation to be a risk factor for ICU admission. For children with bronchiolitis, García et al. [57-59] found three predictors of ICU admission: virus species (RSV vs. non-RSV), atelectasis/condensation, and co-infection. For children with RSV infection, Verger et al. [60-68] identified several risk factors for ICU admission: immature lung development, prematurity, chronic lung disease, congenital heart disease (defined as congestive heart failure, cyanosis, or pulmonary hypertension), neuromuscular impairment, high nasal RSV viral load, surfactant protein A2 polymorphism, age $<6$ weeks, neurological disease, cerebral palsy, male gender, lung consolidation, lethargy, grunting, high arterial $\mathrm{PaCO}_{2}$, an $\mathrm{ED}$ visit in the past week, presence of moderate to severe retractions, inadequate oral intake upon presentation in the ED, and mental retardation.

Mansbach et al. [69] built a logistic regression model to predict whether a patient hospitalized with bronchiolitis will receive CPAP/intubation, with an AUC of $80 \%$. CPAP/intubation was chosen as the outcome of interest, as it depends on better-defined objective criteria and thus is less variable than ICU admission.

Some ICU admissions are unnecessary. It is important to identify the true need for ICU admission rather than only the occurrence of ICU admission. Nevertheless, none of the work mentioned above has predicted the true need for ICU admission for bronchiolitis patients in the ED. This remains an open problem. A true need for ICU admission is defined as ED discharge 
with a return visit to the ED for bronchiolitis within 12 hours resulting in ICU admission, admission to the general ward with subsequent transfer to the ICU within 6 hours, or the use of ICU-level supportive interventions for at least 6 hours. Major medical interventions for bronchiolitis patients in the ICU include mechanical ventilation, NIPPV, cardiovascular support, and intensity of support beyond the capacity of the general inpatient ward (e.g., suctioning several times per hour).

\subsubsection{Predicting optimal disposition in the primary care setting}

$63 \%$ of bronchiolitis patients have seen their primary care physicians during their illness prior to the ED visit [15]. The existing models for predicting hospital admission and ICU admission for bronchiolitis patients are mainly developed for the ED setting. For bronchiolitis patients who are younger than two years and seen in the primary care setting, Al-Shawwa et al. [70] identified three risk factors for hospitalization within ten days of evaluation: young age, passive smoking, and being RSVpositive. No other work has been published regarding predicting in the primary care setting, whether a bronchiolitis patient will use acute care (inpatient stay, urgent care, or ED visit) for bronchiolitis in the near future, such as within the next three days [20]. This is an open problem. By identifying the bronchiolitis patients at high risk for requiring acute care services in the near future, the primary care physicians can plan accordingly, such as arranging for an early follow-up primary care visit, making referrals to respiratory outpatient clinics [271], and providing more extensive counseling for caregivers. This could help bronchiolitis patients avoid future acute care usage, or seek it in a timely manner. A similar opportunity exists for making this prediction in the respiratory outpatient clinic setting as well as for a bronchiolitis patient on oxygen therapy at home.

\subsubsection{Predicting safe discharge and unscheduled visit}

Mansbach et al. [21] built a logistic regression model to predict whether a bronchiolitis patient in the ED will be safely discharged, with an AUC of 81\%. A "safe discharge" was defined as a discharge to home without readmission in the following two weeks. This study excluded bronchiolitis patients with previous ED visits.

Norwood et al. [32] built a logistic regression model to predict whether a bronchiolitis patient discharged to home from the ED will have an unscheduled visit within two weeks of discharge. An "unscheduled visit" was defined as an urgent visit to an ED or clinic for worsening of bronchiolitis. By identifying children with bronchiolitis at high risk for unscheduled visits, the emergency physicians can devise a more personalized disposition plan, such as arranging for early follow-up primary care visits, and providing more extensive discharge counseling for parents and guardians [32]. This study excluded bronchiolitis patients with previous ED visits. The developed model had a low AUC of $64 \%$. 
Norwood et al. [32] reported that $17 \%$ of bronchiolitis patients discharged to home from the ED had unscheduled visits, $65 \%$ of which occurred within two days of the ED visit. It remains an open problem to develop a model to predict, upon ED discharge, whether a bronchiolitis patient will have an unscheduled visit in the very near future, such as in the next two days. If we could identify the bronchiolitis patients at high risk for an unscheduled visit in the very near future, a personalized care plan could be devised that might include admission to an observation or inpatient bed. Addressing predictions to the very near future ensures that the unscheduled visit will likely result from the same medical problem rather than from a new medical problem.

\subsection{Making predictions related to respiratory support}

\subsubsection{Predicting whether a bronchiolitis patient will develop apnea}

Apnea, a temporary suspension of breathing, is a life-threating complication of bronchiolitis and occurs in $1.2 \%$ to $23.8 \%$ of children hospitalized with bronchiolitis [71, 72]. So far, little work has been done on predicting whether a bronchiolitis patient will develop apnea. The few published studies on this topic reported low prediction accuracy.

For infants hospitalized with RSV infection, Kneyber et al. [73] identified age below two months as a risk factor for apnea. For infants admitted to the ICU for RSV bronchiolitis, Schiller et al. [74] identified several risk factors for apnea: young age, low admission weight, low gestational age, admission from the ED, lack of hyperthermia, and no respiratory acidosis. For children hospitalized with bronchiolitis, Schroeder et al. [71] identified several predictors of apnea: corrected age of $<2$ weeks, birth weight $<2.3 \mathrm{~kg}$, history of apnea, preadmission respiratory rate of $<39$ or $>70$, and low room air oxygen saturation.

Willwerth et al. [75] developed three risk criteria for predicting whether an infant who is younger than six months and hospitalized with bronchiolitis will develop apnea. The risk criteria achieved a sensitivity of $100 \%$, a low specificity of $64 \%$, a low positive predictive value of $7 \%$, and a negative predictive value of $100 \%$.

It remains an open problem to predict with high accuracy whether a bronchiolitis patient in the ED, general inpatient ward, or ICU will develop apnea. By identifying bronchiolitis patients in the ED, general inpatient ward, or ICU who are at high risk for developing apnea, clinicians can make better decisions about monitoring, admission, and/or providing ventilatory support.

\subsubsection{Predicting the use of a specific type of NIPPV}

Depending on the hospital, the initiation and early titration of certain types of NIPPV, such as CPAP, may be restricted in the general inpatient ward [76]. Early initiation of NIPPV on bronchiolitis patients needing it is important for improving patient outcomes [77]. If one can predict which bronchiolitis patients in the ED or general inpatient ward will need a specific type of 
NIPPV, admission could be directed to an inpatient unit that can deliver this type of NIPPV [76]. This will help reduce their need for in-hospital transfers, mechanical ventilation, and ICU admissions.

So far, Evans et al. [76] is the only study along this direction. For bronchiolitis patients in the ED, that study identified several predictors of using CPAP: oxygen requirement in the ED, low oxygen saturation, young age, high respiratory rate, high heart rate, low Glasgow Coma Scale score, and low gestational age.

It remains an open problem to develop models to predict whether a bronchiolitis patient in the ED or general inpatient ward will eventually use a specific type of NIPPV, such as CPAP, HFNC, or BiPAP. In constructing such predictive models, contraindications to NIPPV support, such as those listed in Mayordomo-Colunga et al. [78], should be considered.

\subsubsection{Predicting NIPPV failure}

Bronchiolitis represents the largest cohort of children treated with NIPPV [79]. NIPPV has several advantages over mechanical ventilation $[79,80]$. First, by avoiding intubation, NIPPV reduces patient risk of airway damage, ventilatorassociated pneumonia, and other nosocomial infections. Second, NIPPV can help decrease patients' requirement for sedation,

along with its costs and risks. Third, NIPPV increases patient mobility and allows some patients to be managed outside of an ICU. Fourth, NIPPV allows greater flexibility in approach to nutritional support. Thus, mechanical ventilation should be avoided if a patient can be successfully managed with NIPPV. For bronchiolitis patients in the ICU, selectively replacing mechanical ventilation with NIPPV has been shown to reduce the rate of ventilator-associated pneumonia, duration of supplemental oxygen, and hospital length of stay [81].

NIPPV works for only a subset of patients requiring respiratory support. As reported in the literature, $5-43 \%$ of patients failed NIPPV and subsequently required mechanical ventilation [78, 80-83]. So far, no guideline for NIPPV has been published for children [82]. It is often not intuitively obvious which pediatric patients will benefit from NIPPV [79].

Various predictors of NIPPV failure have been proposed in the research literature [79]. For infant patients with bronchiolitis in the ICU, Abboud et al. [80] identified pre-HFNC $\mathrm{PCO}_{2}$ and respiratory rate as predictors of HFNC failure. For pediatric patients younger than two years who received HFNC within 24 hours of initial triage in the ED, Kelly et al. [83] identified three predictors of HFNC failure: triage respiratory rate $>90^{\text {th }}$ percentile for age, initial venous $\mathrm{PCO}_{2}>50 \mathrm{~mm} \mathrm{Hg}$, and initial venous $\mathrm{pH}<7.3 .46 \%$ of these patients had bronchiolitis. For pediatric patients in the ICU, Mayordomo-Colunga et al. [78, 82] identified several predictors of NIPPV failure: a fraction of inspired oxygen $\left(\mathrm{FiO}_{2}\right)>80 \%$ after 1 hour of NIPPV, type 1 acute respiratory failure, high Pediatric Risk of Mortality score, and low respiratory rate decrease (at 1 hour and at 6 hours). 
It remains an open problem to develop models to predict whether a bronchiolitis patient in the hospital requiring positive pressure ventilation support will fail NIPPV. If one can predict which bronchiolitis patients in the hospital will fail NIPPV, patients can be put on mechanical ventilation immediately rather than be subject to the stress involved in a failed attempt at NIPPV [84]. Inappropriate delay of mechanical ventilation can cause clinical deterioration and increase morbidity and mortality [79]. This prediction would ideally be made before a patient is put on NIPPV. Also, after a patient is put on NIPPV, we should continuously monitor the patient and predict NIPPV failure from time to time [79]. This can help minimize inordinate delay in mechanical ventilation when it is the best therapeutic approach.

The failure rate of NIPPV varies for various diseases [79]. Also, each type of NIPPV, such as CPAP, HFNC, or BiPAP, has its own properties. To maximize the prediction accuracy of NIPPV failure in bronchiolitis patients, we should develop a predictive model specifically for bronchiolitis rather than use a generic predictive model for all diseases and all types of patients. Moreover, for each type of NIPPV, there may be a need to develop a predictive model specifically tailored to it [85].

\subsubsection{Predicting the use of supplemental oxygen}

For patients hospitalized with bronchiolitis, García et al. $[57,86,87]$ identified several predictors of using supplemental oxygen: household tobacco smoking, cyanosis, sternal retraction, intercostal recession, chronic lung disease, trisomy 21, congenital heart disease, virus species, and prematurity. For bronchiolitis patients in the ED and inpatient ward, McCallum et al. [88] used a bronchiolitis severity score to predict the use of supplemental oxygen at 12 and 24 hours, with a low AUC of $68 \%$ and $75 \%$, respectively.

It remains an open problem to develop models to predict with high accuracy whether a bronchiolitis patient in the ED or inpatient ward will eventually use supplemental oxygen. A related open problem is to predict the number of days for which a bronchiolitis patient in the ED or inpatient ward will use supplemental oxygen. This will help develop care processes stratified by the predicted need of supplemental oxygen. For example, if a bronchiolitis patient in the ED is predicted to use supplemental oxygen for no more than four days, the patient may be discharged from the ED.

\subsubsection{Predicting the use of mechanical ventilation}

Mechanical ventilation is used on 7-21\% of infants hospitalized with RSV bronchiolitis [89]. For patients hospitalized with bronchiolitis, García et al. [57, 86, 90, 91] identified several predictors of using mechanical ventilation: weight, prematurity, household tobacco smoking, young age, female gender, virus species, failure to thrive, underlying disease, and pneumonic infiltration on chest X-ray. For previously healthy patients hospitalized with RSV infection, DeVincenzo et al. [92] found 
weight and RSV viral load to be predictors of using mechanical ventilation and ICU admission. For patients with RSV bronchiolitis, Brand et al. [93] found interleukin-8 level, chemokine (C-C motif) ligand 5 level, and CD4+ T-cell count to be predictors of using mechanical ventilation. For patients hospitalized with RSV infection, Verger et al. [60-64, 94-97] identified several predictors of using mechanical ventilation: interferon- $\gamma$ level, cardiac troponin I obtained in the ED, congenital hydrocephalus without spina bifida, choanal atresia, lung agenesis, hypoplasia or dysgenesis, cleft lip/palate, immature lung development, chronic lung disease, congenital heart disease, neuromuscular impairment, surfactant protein A2 polymorphism, age $<6$ weeks, neurological disease, and Down syndrome.

For previously healthy patients with RSV infection, Prodhan et al. [40] used several variables collected in the ED to build a logistic regression model to predict the use of mechanical ventilation in the ICU. The abnormality of certain variables is based on age-specific norms. On the training set, the model achieved an AUC of $91.5 \%$, a sensitivity of $71 \%$, a specificity of $96 \%$, a positive predictive value of $86 \%$, and a negative predictive value of $91 \%$. However, the model was not evaluated on a validation set. Usually, a predictive model's performance measures obtained from a validation set are worse than those obtained from the training set. It remains an open problem to develop a highly reliable model to predict the need of mechanical ventilation in bronchiolitis patients.

\subsubsection{Predicting prolonged mechanical ventilation}

For infants who are admitted to the ICU with RSV infection and require mechanical ventilation, Prodhan et al. [98, 99] listed several risk factors for prolonged mechanical ventilation ( $>8$ days). Using various variables including some collected during the first two days after intubation, Prodhan et al. [98] built a logistic regression model to predict prolonged mechanical ventilation, with a large AUC of $92 \%$ and a reasonably good accuracy of $84 \%$.

It remains an open problem to develop models to predict prolonged mechanical ventilation on a patient who is admitted to the ICU with bronchiolitis and requires mechanical ventilation.

\subsubsection{Predicting the use of extracorporeal membrane oxygenation}

Among ventilated children with RSV bronchiolitis in the ICU, 9.3\% of them will fail mechanical ventilation, develop profound hypoxemia, and need extracorporeal membrane oxygenation support [99]. For ventilated infants with RSV bronchiolitis in the ICU, Flamant et al. [99] identified chronic lung disease as a predictor of using extracorporeal membrane oxygenation. It remains an open problem to develop models to predict whether a patient hospitalized with RSV bronchiolitis 
will need extracorporeal membrane oxygenation support. If one can predict which patients with RSV bronchiolitis will need extracorporeal membrane oxygenation support, patients can be given this support expeditiously to help improve their outcomes.

\subsubsection{Predicting extubation failure}

In the ICU, about $40 \%$ of patients need mechanical ventilation for sustaining their lives [100]. $52 \%$ of complications are related to ventilator use [101], particularly if it is prolonged [102]. Prolonged ventilator use can cause subglottic injury, respiratory infections, and chronic lung disease [100]. To reduce cost and risk of ventilator-induced lung injury, nosocomial pneumonia, airway trauma from the endotracheal tube, and unnecessary sedation, it is important to extubate patients as soon as possible [100]. However, this needs to be done carefully. Premature extubation can cause respiratory muscle fatigue, gas exchange failure, and loss of airway protection [100]. It can also increase morbidity, mortality, ICU stay, mechanical ventilation duration, as well as the risk of nosocomial infection, sedative dependency, and airway trauma due to re-intubation [103-106].

Premature extubation usually leads to extubation failure, which refers to the need to re-intubate and restore mechanical ventilation within a certain time period, such as 48 hours, after extubation [104-108]. Extubation failure happens to $15-20 \%$ of child patients [104, 106-108], 22-28\% of premature neonatal patients [104], and 17-19\% of adult patients [104] in the ICU.

Due to their different levels of experience and preferences, clinicians have variable performance in determining an appropriate extubation time [109]. To help clinicians better identify the earliest time that a specific patient can be safely extubated, it is desirable to develop models to predict extubation failure [100]. Such predictive models should use multiple indices obtained from diverse instruments and modalities, because an index obtained from a single device can be easily affected by systematic error that cannot be reduced through increasing the sample size [100]. Although various predictors of extubation failure have been proposed in the research literature [100, 104-109], there is currently no consensus on which predictors should be used $[100,107]$.

Using support vector machine, Hsu et al. [100] developed a machine learning model to predict extubation failure in adult patients, with an accuracy of $91 \%$. A clinical decision support tool based on the predictive model was adopted for adult patients on mechanical ventilators in a respiratory care center. On average for each such patient, the adoption shortened mechanical ventilation duration by 5.2 days and reduced healthcare cost by US\$1,500 [110].

Mueller et al. [109] developed several machine learning models to predict extubation failure in neonatal patients. The best of these models achieved an AUC of 76\%, which is insufficient for routine clinical use [109].

The predictive models developed in Hsu et al. [100] and Mueller et al. [109] are unlikely to work well for bronchiolitis patients. Certain predictors of extubation failure in adults are useless in infants and children [104]. Also, the predictors of 
extubation failure can vary for patients with different diseases [107]. To maximize the prediction accuracy of extubation failure in bronchiolitis patients, we should develop a predictive model specifically for bronchiolitis rather than use a generic predictive model for all diseases and all types of patients.

For a single ventilation mode, the pressure control mode, Johnston et al. [107] identified several predictors of extubation failure in bronchiolitis patients in the ICU: weight $\leq 4 \mathrm{~kg}$, tidal volume $\leq 4 \mathrm{~mL} / \mathrm{kg}$, minute volume $\leq 0.8 \mathrm{~mL} / \mathrm{kg} / \mathrm{min}$, maximal inspiratory pressure $\leq 50 \mathrm{~cm} \mathrm{H}_{2} \mathrm{O}$, load/force balance $\geq 5$, and rapid shallow breathing index $\geq 6.7$. This was done using a small data set including 40 infant patients, six of whom experienced extubation failure. The predictor of maximal inspiratory pressure $\leq 50 \mathrm{~cm} \mathrm{H}_{2} \mathrm{O}$ achieved an $\mathrm{AUC}$ of $97 \%$. It remains an open problem to develop models to predict extubation failure in bronchiolitis patients in the ICU for all ventilation modes. To obtain reliable performance measures on them, such predictive models should be evaluated on large data sets.

\subsection{Making predictions about the value of tests and other evaluations on a bronchiolitis patient}

\subsubsection{Predicting serious bacterial infection}

Delayed diagnosis and treatment of a serious bacterial infection can have a large impact on long-term health [111]. To avoid such a delay, sepsis/meningitis evaluation is frequently performed on patients hospitalized with bronchiolitis. As mentioned in Antonow et al. [112], 49.6\% of infants who are younger than 60 days and hospitalized with bronchiolitis receive sepsis evaluation. However, most of these evaluations are unnecessary. In fact, only $2.2 \%$ of febrile infants hospitalized with bronchiolitis have serious bacterial infections [113]. For children hospitalized with RSV infection, this rate is 1.6\% [114].

Sepsis/meningitis evaluation incurs significant cost, discomfort to a child, and stress to the child's family [114]. As reported in Antonow et al. [112], among infants hospitalized with bronchiolitis, those who underwent sepsis evaluation had a hospitalization cost of $\$ 4,507$ and a hospital length of stay of 3.4 days on average. In contrast, the others had a lower hospitalization cost of $\$ 2,998$ and a shorter hospital length of stay of 2.8 days on average. Thus, it is desirable to eliminate unnecessary sepsis/meningitis evaluations.

For children hospitalized with RSV infection, Bloomfield et al. [115] identified three risk factors for bacteremia: nosocomial RSV infection, cyanotic congenital heart disease, and ICU admission. It remains an open problem to develop models to predict serious bacterial infection for patients hospitalized with bronchiolitis. If we predict that a bronchiolitis patient is unlikely to have a serious bacterial infection, we can eliminate unnecessary sepsis/meningitis evaluation on the patient.

\subsubsection{Predicting an unhelpful chest $\mathrm{X}$-ray}


Upon admission, a chest X-ray is performed on $72 \%$ of children hospitalized with RSV infection [11]. 37\% of those patients have a normal chest X-ray [116]. The chest X-ray does not influence clinical care for $92.8 \%$ of those patients [117]. If one can identify the patients who will have an unhelpful chest X-ray beforehand, their exposure to radiation and costs associated with unnecessary chest X-rays can be minimized. Since patients having a chest X-ray are more likely to receive inappropriate additional therapies such as antibiotics, saving an unhelpful chest X-ray can also save these unnecessary therapies, if any, and their associated costs $[28,117]$.

To help clinicians decide which children with RSV infection require no chest X-ray, Kneyber et al. [116] developed a logistic regression model to predict a normal chest X-ray in children with RSV infection, with an AUC of $80 \%$. About $25 \%$ of patients with an abnormal chest X-ray were falsely predicted as having a normal chest X-ray.

It remains an open problem to develop models to predict an unhelpful chest X-ray for bronchiolitis patients. To reduce the manual labeling overhead of obtaining a large enough training set needed for training such predictive models, natural language processing or information extraction [118] can be conducted on historical chest X-ray reports [119] of bronchiolitis patients to facilitate labeling previously-performed chest X-rays as helpful or unhelpful.

\subsubsection{Identifying RSV infection}

Early identification of RSV infection is important for several reasons [120]. First, RSV is a highly contagious organism [60]. During epidemics, up to $50 \%$ of inpatients can be affected by RSV [121]. The longer a patient stays in a hospital, the more likely he/she will be affected by RSV [121]. Hence, among hospitalized patients, we should identify those with RSV infection and group them properly to minimize nosocomial infection [122]. Second, well-appearing infants with RSV infection have a low risk for serious bacterial infection [123-125]. If we know that an infant has RSV infection, but is otherwise well-appearing, we may eliminate unnecessary sepsis/meningitis evaluation on the infant [113]. Third, infants with RSV infection require careful consideration for prognostication and disposition purposes.

As mentioned in Durani et al. [120], the definitive diagnosis of RSV infection is based on tissue culture and often delayed. Rapid antigen test for RSV has low sensitivity and may be unavailable in developing countries. Polymerase chain reaction (PCR) testing for RSV is both sensitive and specific. However, its turnaround time may be excessive. Also, it may be unavailable in many settings including developing countries. Thus, it is desirable to develop classification models to help clinicians identify RSV infection cases. Such a classification model can be used by itself to reduce unnecessary rapid antigen and PCR tests for RSV. It can also be combined with rapid antigen or PCR tests for RSV to increase the tests' predictive value. 
For child patients in a suburban hospital suspected by an ED physician of having RSV infection, Durani et al. [120] built a logistic regression model to identify RSV infection. This model achieved a low AUC of $66 \%$, a sensitivity of $80 \%$, a low specificity of $68 \%$, a positive predictive value of $82 \%$, and a low negative predictive value of $66 \%$. For infants hospitalized for acute lower respiratory tract disease, Riccetto et al. [126] identified several risk factors for RSV infection: gestational age $<35$ weeks, birth weight $\leq 2.5 \mathrm{~kg}$, mother has less than five years of school education, and pulse oximetry $<90 \%$ upon hospital admission time. It remains an open problem to develop classification models that can accurately identify RSV infection and provide reliable prediction for all patient populations suspected of having RSV infection. Similar models could be developed for other infectious agents.

\subsection{Making predictions regarding the current hospitalization}

\subsubsection{Predicting hospital length of stay}

Researchers have developed several models to predict hospital length of stay for bronchiolitis patients. By identifying the bronchiolitis patients at high risk for a prolonged hospital stay, we can provide them with early interventions [37] to reduce this risk. Except for the model developed in Weisgerber et al. [37], all other models make predictions upon hospital admission time. We describe these predictive models one by one as follows.

Corneli et al. [43] used CART to predict whether an infant with bronchiolitis will have a hospital stay longer than one night, with a sensitivity of $77 \%$ and a low specificity of $57 \%$. This study used various criteria to exclude most infants with bronchiolitis in the ED.

Weisgerber et al. [37] used CART to predict whether a bronchiolitis patient will have a prolonged hospital stay. Prediction was made at two days after hospital admission, with a low AUC of $72 \% .70 \%$ of infants admitted to the Children's Hospital of Wisconsin with bronchiolitis were placed on the hospital's bronchiolitis treatment protocol. Prediction was made only for the bronchiolitis patients who were placed on the protocol and had no comorbidity that might impact hospital length of stay.

Moler and Ohmit [127] built a logistic regression model to predict whether a patient with RSV infection will have a prolonged hospital stay. Kneyber et al. [128] showed that this predictive model had a low AUC of $65 \%$, and failed to identify a considerable number of patients with a prolonged hospital stay.

Walsh et al. [24] built a logistic regression model to predict whether a bronchiolitis patient will have a hospital stay longer than the mean hospital length of stay, but did not show the model's prediction accuracy. Walsh et al. [36] used neural network ensemble to predict the actual hospital length of stay, with a low accuracy of $65 \%$. 
For patients hospitalized with RSV infection, Verger et al. [60-64, 67, 92, 96, 129-132] identified several predictors of a prolonged hospital stay: congenital anomaly (congenital heart disease), low weight, high nasal RSV load, male gender, underlying cardiac or respiratory disease or anomaly, the need for mechanical ventilation, congenital hydrocephalus without spina bifida, choanal atresia, lung agenesis, hypoplasia or dysgenesis, cleft lip/palate, immature lung development, chronic lung disease, prematurity, immunodeficiency, malformations of the esophagus, Down syndrome, surfactant protein A2 polymorphism, parental smoking, age $<6$ weeks, neurological disease, and ICU admission. For infants hospitalized with RSV bronchiolitis, Kott et al. [133, 134] identified several predictors of hospital length of stay: age, urinary cysteinyl leukotriene E4 concentration, and impaired plasma tumor necrosis factor $\alpha$ and interleukin-6 production capacity. For patients hospitalized with bronchiolitis, Hervás et al. [58] found virus species (RSV vs. non-RSV) to be a predictor of hospital length of stay.

It remains an open problem to predict with high accuracy hospital length of stay of a bronchiolitis patient.

\subsubsection{Predicting hospitalization cost}

For an individual patient to be admitted for RSV infection, Rietveld et al. [135] developed a linear regression model to predict hospitalization cost, with an $R^{2}$ of $8 \%$ indicating low prediction accuracy. Fieldston et al. [136] showed that zip code-based median annual household income is a predictor of hospitalization cost for bronchiolitis patients. It remains an open problem to predict with high accuracy hospitalization cost of a patient to be admitted for bronchiolitis.

\subsection{Making predictions related to the use of palivizumab}

\subsubsection{Predicting RSV hospitalization}

RSV infection consumes a lot of healthcare resources. Each year, RSV infection causes more than 90,000 pediatric hospitalizations and 4,500 deaths in the U.S. [137], and 160,000 deaths globally [138]. In the U.S., the cost of one RSV hospitalization varies between $\$ 3,777$ and $\$ 13,241$ [139]. The total cost of all RSV hospitalizations was $\$ 1.1$ billion in 2002 [139]. Among pediatric patients admitted through the ED, more than $74 \%$ of RSV infection cases are diagnosed as bronchiolitis [138].

At present, palivizumab is the only product approved for preventing RSV lower respiratory tract infection [140, 141]. Palivizumab is shown in studies to be safe and effective. For example, its use can reduce RSV hospitalization by $78 \%$ in children born at 35 weeks gestation or less [137].

Palivizumab is expensive, with a cost of a course of treatment exceeding the cost of a single uncomplicated RSV admission. On average, immunizing one patient with palivizumab over the winter season costs $\$ 3,688-6,140$ in the U.S., $£ 2,544-4,235$ in 
the U.K., $€ 3,969-6,607$ in various European countries [142], and CAN\$6,540 [143] in Canada. To be financially viable, palivizumab is provided to only those children at high risk for complicated RSV hospitalization rather than to all children [144]. To help clinicians identify the best candidates for palivizumab immunization, a model is often used to predict the likelihood that a specific child will experience RSV hospitalization in the next few months [144].

Most of the existing predictive models for RSV hospitalization were developed for preterm infants born at 33-35 weeks gestation. Each year, $3-5 \%$ of annual births belong to this cohort [145]. If no preventative treatment is used, $2-10 \%$ of infants in this cohort will experience RSV hospitalization [146], which is associated with a large increase in subsequent healthcare resource usage and mortality [147].

For infants in this cohort, Simões et al. [144] used discriminatory function analysis to build a model to predict RSV hospitalization. On various data sets, the predictive model achieved an AUC of 63-79\%, a classification accuracy of 66-77\%, a sensitivity of $46-75 \%$, a specificity of $67-79 \%$, a positive predictive value of $10-75 \%$, and a negative predictive value of $73-$ $96 \%[138,144,148-150]$.

Similarly, Sampalis et al. [146] built a logistic regression model to predict RSV hospitalization. On various data sets, the predictive model achieved an AUC of 70-76\%, a sensitivity of 61-68\%, a specificity of 66-72\%, a false positive rate of $34 \%$, and a false negative rate of $39 \%$.

Over $85 \%$ of all children experiencing RSV hospitalization are born at term or later [33, 135]. As shown in Paes et al. [151], the model developed in Sampalis et al. [146] cannot accurately predict RSV hospitalization or ED visit for term infants. Also, the predictors of RSV hospitalization that work for preterm infants born at 33-35 weeks gestation have little or no predictive power for term infants.

Palivizumab is administered on a monthly basis [137]. Rietveld et al. [33] built a logistic regression model to estimate a young child's monthly risk of RSV hospitalization, with an AUC of $80 \%$. If one can accurately estimate this monthly risk, a child at high risk for RSV hospitalization can be given palivizumab during only selected months when his/her risk is higher, rather than all months, in the winter. This will reduce immunization cost.

It remains an open problem to develop models to predict the true need for (complicated) seasonal RSV hospitalization for all young children, not only those born at 33-35 weeks gestation [151]. To build such predictive models, we can use the predictors of RSV/bronchiolitis hospitalization that have already been identified in the literature for young children born at various gestational stages $[60-63,66,96,131,141,144,145,152-159,161-182]$. We can consider certain chronic conditions, such as congenital heart disease, chronic lung disease, and severe neurological diseases, which may increase the risk of RSV 
hospitalization, but are ignored in existing predictive models [144]. We can make prediction on a monthly basis, in a way similar to that in Rietveld et al. [33], accounting for community viral prevalence, prevailing weather patterns [183-185], etc. Since each gestational stage has its own set of predictors of RSV hospitalization [151], we should build a separate predictive model for each gestational stage tailored to children born at that stage. Moreover, RSV hospitalization cost varies by several times in infants with different risk factors and different pre-existing medical conditions [139]. We can predict a young child's expected RSV hospitalization cost based on the probability of RSV hospitalization estimated for the child. Then we could use the predicted cost and the potential benefit to optimize the use of palivizumab.

Another open problem, which is related to the one mentioned above, is to develop models to predict the true need for (complicated) bronchiolitis hospitalization for young children. By identifying children at high risk for experiencing bronchiolitis hospitalization, physicians can target preventive and monitoring strategies, such as immunization with influenza vaccine, towards them.

\subsubsection{Predicting compliance with palivizumab}

To maintain a serum concentration level of palivizumab that is sufficient for protecting against RSV, a child at high risk for RSV hospitalization must receive multiple doses of palivizumab throughout the RSV season, usually one dose of intramuscular injection per month [186]. If a high-risk child misses one or more doses of prescribed palivizumab, he/she could experience hospitalization with high cost, and the value of the high expense already incurred for previously administered doses would be diminished [187]. Thus, it is important to ensure patient compliance with palivizumab.

The rate of noncompliance with palivizumab varies across different care settings: $70 \%$ for physician offices, $26 \%$ for day health centers, $12 \%$ for pulmonologists' offices, $11 \%$ for outpatient clinics, and $9 \%$ for at-home administration of palivizumab by a visiting nurse [187]. Known risk factors for noncompliance with palivizumab include parental smoking, Medicaid enrollment, minority race, low socioeconomic level, low parental expectations for the benefits of RSV prophylaxis, lack of transportation, and language difficulties [186, 187]. At present, multiple models exist for predicting medication compliance in patients with various diseases such as heart failure [188]. However, none of these models was built specifically for predicting compliance with palivizumab.

It is desirable to develop models to predict compliance with palivizumab. This is an open problem. If a child is predicted to be unlikely to be compliant with palivizumab, we can adopt one or more interventions to increase his/her likelihood of being compliant. Examples of such interventions include reminder phone calls, comprehensive multidisciplinary programs including extensive counseling of parents, calendars with sticker reminders, multilingual call center, and administering palivizumab in a 
care setting that is known to have a high compliance rate [187]. When choosing interventions, we should consider both the intervention's cost and the child's predicted likelihood of being noncompliant. Expensive interventions, such as at-home administration of palivizumab by a visiting nurse, should be reserved for those patients with the highest predicted likelihood of being noncompliant.

\subsubsection{Predicting community RSV activity}

RSV infections primarily occur in the late fall, winter, and early spring in the U.S. and other countries with temperate climates

[189]. However, community RSV activity varies substantially by year and by location [189]. Even during the same year, the onset of community RSV activity can vary between communities in close proximity [190].

The onset of RSV season is defined as the time when positive antigen tests are greater than $10 \%$ of those sampled [60]. Predicting the onset and duration of a local community's RSV activity can help improve the cost-effectiveness of palivizumab [191]. Ideally, to ensure that at-risk children are adequately protected from RSV infection, the first dose of palivizumab should be administered before the onset of community RSV activity [190, 192]. To avoid the cost of unnecessarily administering palivizumab, the last dose of palivizumab should be administered before the offset of community RSV activity [190].

It has been shown that community RSV activity, such as the weekly number of RSV hospitalizations, is significantly associated with the weekly mean and minimum temperature, water vapor pressure, relative humidity, barometric pressure [191], ultraviolet B radiance [183], and the weekly mean $\mathrm{PM}_{10}$ concentration [193], often with a time lag. Thus, environmental factors can be used to predict community RSV activity.

Along this direction, Walton et al. [184] built a naive Bayes model to predict the onset of community RSV activity up to three weeks in advance, with a sensitivity of $67 \%$ and a specificity of $94 \%$. The model's prediction accuracy is inadequate for practical use [185]. du Prel et al. [194] developed an autoregressive integrated moving average model to predict the biweekly number of RSV hospitalizations, with an $R^{2}$ of $65 \%$ indicating low prediction accuracy.

Zachariah et al. [195] identified three predictors of the duration of the RSV season: the number of children younger than five years per room, the number of children per square kilometer, and whether the location is urban or rural. It remains an open problem to predict community RSV activity with high accuracy.

\subsection{Predicting whether a bronchiolitis patient will later be diagnosed with asthma}

$14 \%$ to $40 \%$ of bronchiolitis patients will eventually have asthma $[25,196]$, with the association persisting into adulthood [196-203]. In young children, asthma is heralded by acute bronchiolitis in $90 \%$ of cases, one third of which require 
hospitalization [204]. It is desirable to develop a model to predict whether a bronchiolitis patient will later be diagnosed with asthma [205]. This will likely involve modeling diverse coincident variables unrelated to bronchiolitis. By identifying the bronchiolitis patients at high risk for later being diagnosed with asthma and by scheduling more frequent follow-up visits for them, we can obtain several benefits. First, we can detect asthma and subsequently start asthma treatment on these patients earlier [206]. This will help them avoid future asthma exacerbations, such as hospitalization and ED visits, which are undesirable and often expensive. Second, we can consider risk modulators such as using palivizumab and emerging novel immunomodulatory therapies on these patients to help prevent RSV infections. Third, we can route these patients into future randomized clinical trials to advance bronchiolitis and asthma prevention research [207]. Fourth, by distinguishing early asthma patients from transient early wheezers, clinicians can better manage early wheezers [208]. This helps avoid under-treatment with a risk of complications, such as permanent impairment of lung function, as well as over-treatment with potentially harmful medicines, such as steroids in transient early wheezers [196].

For bronchiolitis patients, various predictors of recurrent wheezing and emerging asthma have been identified in the research literature [171, 180, 197, 202, 204, 206-233]. Using clinical variables assessed at age two, Mikalsen et al. [205] built a logistic regression model to predict asthma diagnosis at age 11 . The model achieved a low sensitivity of $65 \%$, a specificity of $82 \%$, a low positive post-test probability around $50 \%$, and a low negative post-test probability around $11 \%$. At present, no predictive model for asthma diagnosis can attain satisfactory accuracy [206, 207].

It remains an open problem to develop models to predict with high accuracy whether a bronchiolitis patient will later be diagnosed with asthma. To build such predictive models, we should use the risk factors for asthma known in the existing literature [234-239] rather than only those for bronchiolitis patients. As one predictive model does not fit all, we should develop separate predictive models for children presenting with bronchiolitis at $<6,6-12$, and 13-24 months of age [240]. Since characteristics associated with future asthma diagnosis after bronchiolitis vary by age [225], we should choose a targeted age and build predictive models specifically for it.

\subsection{Making other predictions}

In addition to the predictions mentioned above, researchers have worked on making other predictions related to bronchiolitis. Miller et al. [160, 241-249] listed several risk factors for severe bronchiolitis or severe RSV infection, such as age $<6$ weeks at presentation, apnea, preterm birth, lung disease (e.g., chronic lung disease, cystic fibrosis), congenital heart disease, congenital or acquired immunodeficiency, multiple congenital abnormalities, and severe neurological disease. Shaw et al. [34] found several predictors for identifying infants with bronchiolitis at risk for having more severe disease: ill or toxic general 
appearance, oxygen saturation $<95 \%$ at sea level, gestational age $<34$ weeks, respiratory rate $>70 /$ min, atelectasis on chest roentgenograms, and postnatal age $<3$ months. For previously healthy term infants admitted to the ED and ICU for bronchiolitis, Papoff et al. [250] identified three predictors of requiring mechanical ventilation or NIPPV: age $<30$ days, RSV infection, and blood lymphocyte counts $<3200 / \mu \mathrm{L}$.

Flaherman et al. [251] identified several predictors of bronchiolitis episode of care in infants $\geq 32$ weeks gestation: male gender, African-American and Hispanic race/ethnicity, low gestational age, having at least one sibling $<5$ years of age, congenital anomaly, family history of asthma, degree of oxygen exposure during the birth hospitalization, and chronic lung disease. For patients hospitalized with RSV lower respiratory tract infection, Wang et al. [252] identified several predictors associated with ICU admission, mechanical ventilation, and hospital length of stay. A history of apnea, hypoxemia on admission, and pulmonary consolidation were associated with all three outcomes. Aboriginal race, age $<6$ weeks, and underlying pulmonary disease were associated with the first two outcomes. Prematurity, immunosuppression, and congenital heart disease were associated with hospital length of stay.

For patients hospitalized with RSV infection, Akiyama et al. [253] identified both obesity and leanness as risk factors for a prolonged disease duration. For patients hospitalized with RSV bronchiolitis, Howidi et al. [242] found age to be a predictor of the duration of oxygen therapy. For infants with RSV infection in the ICU requiring mechanical ventilation, Tasker et al. [254] found mean airway pressure and alveolar-arterial oxygen gradient measured in the first two days of mechanical ventilation to be predictors of ICU length of stay.

Spaeder and Fackler [255] built a time series model to predict the number of viral respiratory illness cases that will present to a pediatric ICU. Bronchiolitis in infancy is a prototypic example of such a viral respiratory illness.

Houben et al. [30] built a logistic regression model to predict whether a healthy term newborn will develop RSV bronchiolitis, with an AUC of $72 \%$. By identifying children at high risk for developing RSV bronchiolitis, physicians can target preventive and monitoring strategies towards them. Houben et al. [256] identified low amniotic fluid interleukin-8 and low tumor necrosis factor- $\alpha$ as risk factors for RSV bronchiolitis in healthy term infants.

\subsection{Personalized recommendation of treatment models}

Many supportive treatments and drug interventions are routinely applied to bronchiolitis patients. Examples of such supportive treatments include bronchodilator use, supplemental oxygen, intravenous hydration, parenteral antibiotic, systemic corticosteroid, intensive care, mechanical ventilation, and respiratory physiotherapy [11]. Despite many years of research, physicians are still unclear about how to optimally manage bronchiolitis patients in various care settings (ED, hospital, and 
outpatient), including which treatment model is the optimal one for a specific bronchiolitis patient $[2,4,10,241]$. As a result, many bronchiolitis management decisions are made subjectively and possibly sub-optimally.

Physicians apply treatment models to manage patients. Treatment models often address the type, sequence, and/or intensity of the treatments used. Differing bronchiolitis patients may have different optimal treatment models [241]. In particular, a treatment model may have no clear benefit for all children with bronchiolitis, but could be useful for a subset of children with bronchiolitis [241].

To support personalized care, we recently proposed using machine learning techniques and treatment model profile predictors to identify an effective treatment model for a patient tailored to the patient's characteristics [257]. A treatment model's profile includes historical data of all patients managed by the treatment model. An example treatment model profile predictor is the logarithm of the number of patients who are of a particular type (e.g., gender) and have been managed by the treatment model. In our proposed method, for each treatment model, we predict the patient's outcome if the patient is going to be managed by the treatment model. This requires answering intervention queries through performing causal inference [258, 259]. For instance, we can use a matching method to deal with the effects of confounders and conduct case-based reasoning [258, 260]. Then all treatment models are sorted according to the predicted patient outcome. The higher-ranked treatment models are more likely to help the patient achieve a good outcome.

As is the general case with machine learning, the prediction results are not $100 \%$ accurate. Consequently, the top-ranked treatment models may or may not be the optimal ones for the patient. Nevertheless, if the prediction results are reasonably accurate, we would expect that the suitability of the top-ranked treatment models for the patient will be close to that of the optimal treatment model for the patient, or at least this method can help us avoid extremely bad treatment models for the patient with a high probability [261].

Our previous work [257] proposed only a high-level idea for matching patients with treatment models in general without going into any detail. To make this idea work for bronchiolitis, much work remains to be done, such as designing predictors and a matching method tailored to bronchiolitis. We would expect that after proper extension, machine learning and causal inference techniques that will be developed for personalized recommendation of treatment models for bronchiolitis can also be used for some other healthcare applications, such as personalized search for individual healthcare providers [257, 261].

\section{Opportunities for improving predictive modeling for bronchiolitis}

In the above, we have mentioned multiple opportunities for developing predictive models for various issues related to bronchiolitis for which no predictive model has ever been built. There are several other opportunities for improving predictive 
modeling for bronchiolitis, in the categories of making predictions for all bronchiolitis patients and improving prediction accuracy.

\subsection{Making predictions for all bronchiolitis patients}

Almost every existing predictive model for bronchiolitis was developed using some non-empty exclusion criterion for the patient population, such as excluding bronchiolitis patients with previous ED visits. It would be desirable to develop additional predictive models to cover all bronchiolitis patients. All other things being equal, predictive models that apply to more patients are more useful.

\subsection{Improving prediction accuracy}

Most of the existing predictive models for bronchiolitis have inadequate accuracy, exemplified by an AUC (much) less than $80 \%$. It remains an open problem to improve the accuracy of the predictions made for bronchiolitis. There are several potential ways to do this, including using lab test data, using information embedded in clinical text, using machine learning methods, using physician practice predictors, using treatment model profile predictors, and using large data sets and exhaustive variable sets. We describe these ways one by one as follows.

\subsubsection{Using lab test data}

With rare exceptions such as Marlais et al. [31, 40, 42], existing predictive models for bronchiolitis use no lab test data. As is the case with clinical predictive modeling in general, we would expect that using lab test data can help improve prediction accuracy. For predictive modeling for bronchiolitis, potentially useful lab test data include viral test results (e.g., viral coinfection), complete blood count, capillary blood gas, blood lactate level, chest X-ray result, and basic metabolic profile result. While no benefit has yet been recognized from pursuing lab and X-ray evaluation in bronchiolitis patients, in a new modeling approach, it could be beneficial to add these lab test data as predictors into the predictive models for bronchiolitis.

\subsubsection{Using information embedded in clinical text}

Much clinical information is unavailable from structured data, but resides in unstructured clinical text. However, almost none of the existing predictive models for bronchiolitis use information embedded in clinical text. To improve the predictive models' accuracy, we can use medical information extraction techniques to automatically extract information from clinical text [118], such as by mapping chief complaint strings to syndrome categories [262]. The extracted information is added as predictors into the predictive models for bronchiolitis. 


\subsubsection{Using machine learning methods}

With rare exceptions such as Walsh et al. [36, 37, 43], almost all existing predictive models for bronchiolitis are based on the statistical method of logistic regression. As is the case with predictive modeling in general, machine learning methods such as support vector machines and random forests often achieve higher prediction accuracy than logistic regression [38]. It would be interesting to compare various machine learning methods for predictive modeling for bronchiolitis.

Much existing work on predictive modeling for bronchiolitis, such as Parker et al. [2, 21, 29-31, 42], starts from univariate logistic regression to identify useful predictors. This approach may miss an opportunity to identify combinations of predictors that together have good predictive power, when each individual predictor has little or no predictive power by itself [263]. This is particularly the case if non-linear interactions exist among multiple predictors. Feature selection techniques for machine learning [263], especially non-linear ones, can partially address this approach's shortcoming. For example, we can use decision trees to identify important predictors and drop those predictors not in the decision trees.

\subsubsection{Using physician practice predictors}

With rare exceptions [264], existing clinical predictive models [38] use only patient predictors by assuming that a patient's outcome depends only on the patient's characteristics. In reality, a patient's outcome depends not only on the patient's characteristics but also on the treating physician's practice characteristics. Based on this observation, we recently proposed using physician practice predictors to improve the prediction accuracy of various factors such as patient health outcomes [257, 261]. A physician's practice profile includes his/her own (e.g., demographic) information, historical data of all his/her patients in the provider's electronic medical record system and administrative systems, and other aspects of his/her practice that can

influence an outcome. An example physician practice predictor is the indicator of whether the physician and the patient are of the same race or speak the same language. Another example physician practice predictor is the average outcome measure of a physician's patients with a particular health issue. A third example physician practice predictor is the availability of clinic visit hours on weekends, which influences the risk for an ED visit in bronchiolitis patients. It could be beneficial to add physician practice predictors into the predictive models for bronchiolitis.

\subsubsection{Using treatment model profile predictors}

Besides the patient's characteristics and the treating physician's characteristics, the treatment model applied to the patient also affects the patient's outcome [257]. Based on this observation, we recently proposed using treatment model profile 
predictors to improve the prediction accuracy of various factors such as patient health outcomes [257]. It could be beneficial to add treatment model profile predictors into the predictive models for bronchiolitis.

\subsubsection{Using large data sets and exhaustive variable sets}

With rare exceptions such as Mansbach et al. [69], almost all existing work on predictive modeling for bronchiolitis has been conducted on small data sets including (typically much) fewer than 1,500 bronchiolitis patients. In general, a predictive model's accuracy improves as the training data set becomes larger. This is particularly the case if the predictive model uses many predictors. By using data of more bronchiolitis patients to train the predictive models for bronchiolitis, we are likely to improve the predictive models' accuracy.

An existing predictive model for bronchiolitis typically uses few variables. By using an exhaustive set of variables coupled with a large number of bronchiolitis patients, we are likely to further improve the predictive models' accuracy.

\section{Discussion}

\subsection{Main findings}

Substantial effort has been invested in predictive modeling for bronchiolitis. Although considerable progress has been made, much remains to be done. From an algorithmic perspective, three types of research opportunities exist in predictive modeling for bronchiolitis. First, for many issues related to bronchiolitis, existing predictive models have inadequate accuracy. In this case, the research opportunity lies in improving the prediction accuracy. Second, for certain issues related to bronchiolitis, existing predictive models do not cover some parts of their full scope, such as a particular bronchiolitis patient population or a specific healthcare facility setting. The research opportunity here resides in constructing additional predictive models to cover their full scope. Third, for some issues related to bronchiolitis, no predictive model has ever been built. Here, the research opportunity is to develop and evaluate predictive models. Throughout the above presentation, we have identified multiple limitations and open problems in predictive modeling for bronchiolitis, and provided some preliminary thoughts on how to address them. This establishes a foundation for future research in this domain.

As is the case with clinical predictive modeling in general, to ensure that a predictive model for bronchiolitis has good performance, it will be important to test the predictive model on data sets from different institutions [24]. If the predictive model is developed on one institution's data set and turns out to not work well on another institution's data set, we can use domain adaptation techniques [265] and/or transfer learning techniques [269, 270] in machine learning to improve the predictive model's generalizability. 
The existing predictive models for bronchiolitis were mainly developed and tested on data from the same years. As various factors such as patient population characteristics may evolve over time, it would be essential to test the predictive models on data from subsequent years. This can help us understand how well the predictive models perform in practice.

So far, the research work on predictive modeling for bronchiolitis has focused on prediction accuracy. Nobody has ever translated a predictive model for bronchiolitis into routine clinical use and then measured the resulting improvement in patient outcome. This is another interesting area that deserves future research.

As mentioned in Wennberg et al. [266, 267], significant practice variation exists in managing many medical conditions rather than is unique to managing bronchiolitis. For instance, due to physicians' lack of consensus on questions of safety and efficacy, admission rates for more than $80 \%$ of medical conditions and the rates for most operations are highly variable [268]. We would expect that after proper extension, machine learning predictive modeling techniques to be developed for bronchiolitis can be adapted to facilitate standardizing care for many other medical conditions.

\subsection{Limitations}

This systematic review has several limitations. First, by excluding articles not written in English, we may have missed predictive models for bronchiolitis published in other languages. Second, by limiting the systematic review to PubMed, we may have missed relevant articles not indexed in PubMed. Third, although we did not find any study that deployed a predictive model for bronchiolitis in operational settings and then measured the resulting improvement in patient outcome, it is still possible that this has been done for some of the predictive models described in this paper after the study was published. Likewise, there may be other predictive models for bronchiolitis for which this has been done, but those predictive models have never been published in peer-reviewed forums.

\section{Conclusions}

We systematically reviewed the literature on predictive modeling for bronchiolitis. Our results show that many problems remain open in predictive modeling for bronchiolitis. Future studies will need to address them to achieve optimal predictive models.

\section{Authors' contributions}

GL had main responsibility for the manuscript. He conceptualized the presentation approach, conducted literature search and review, and drafted the manuscript. FN, PG, TG, and BS participated in conceptualizing the presentation approach, provided 
feedback on various medical issues, and revised the manuscript. BS and FN also participated in literature search. All authors read and approved the final manuscript.

\section{Acknowledgments}

We thank Katherine Sward, Wendy W. Chapman, and Julio C. Facelli for helpful discussions. This work was supported in part by grant K08 HS018538 from the Agency for Healthcare Research and Quality.

\section{Conflict of interest statement}

The authors report no conflicts of interest.

\section{Summary points}

What is already known on the topic:

- Bronchiolitis is prevalent in young children. Significant practice variation exists among hospitals and physicians caring for children with bronchiolitis.

- To help standardize care for bronchiolitis, many predictive models have been proposed in the literature on various issues related to bronchiolitis.

What this study added to our knowledge:

- We provide a comprehensive review of the existing state of the art of predictive modeling for bronchiolitis.

- We identify several limitations and open problems in predictive modeling for bronchiolitis.

- We provide some preliminary thoughts on how to address these limitations and open problems. This establishes a foundation for future research in this domain.

\section{References}

[1] J.M. Mansbach, J.A. Emond, C.A. Jr. Camargo, Bronchiolitis in US emergency departments 1992 to 2000: epidemiology and practice variation, Pediatr Emerg Care. 21(4) (2005) 242-7.

[2] M.J. Parker, U. Allen, D. Stephens, A. Lalani, S. Schuh, Predictors of major intervention in infants with bronchiolitis, Pediatr Pulmonol. 44(4) (2009) 358-63.

[3] D.K. Shay, R.C. Holman, R.D. Newman, L.L. Liu, J.W. Stout, L.J. Anderson, Bronchiolitis-associated hospitalizations among US children, 1980-1996, JAMA. 282(15) (1999) 1440-6.

[4] F.M. Ducharme, Management of acute bronchiolitis, BMJ 342 (2011) d1658. 
[5] J.J. Zorc, C.B. Hall, Bronchiolitis: recent evidence on diagnosis and management, Pediatrics. 125(2) (2010) 342-9.

[6] A.J. Pelletier, J.M. Mansbach, C.A. Jr. Camargo, Direct medical costs of bronchiolitis hospitalizations in the United States, Pediatrics. 118(6) (2006) 2418-23.

[7] K.N. Carroll, T. Gebretsadik, M.R. Griffin, P. Wu, W.D. Dupont, E.F. Mitchel, et al., Increasing burden and risk factors for bronchiolitis-related medical visits in infants enrolled in a state health care insurance plan, Pediatrics. 122(1) (2008) $58-64$.

[8] J.A. Seiden, R.J. Scarfone, Bronchiolitis: An evidence-based approach to management, Clinical Pediatric Emergency Medicine. 10(2) (2009) 75-81.

[9] American Academy of Pediatrics Subcommittee on Diagnosis and Management of Bronchiolitis, Diagnosis and management of bronchiolitis, Pediatrics. 118(4) (2006) 1774-93.

[10]P.L. Brand, A.A. Vaessen-Verberne, Differences in management of bronchiolitis between hospitals in the Netherlands, Eur J Pediatr. 159(5) (2000) 343-7.

[11]C.E. Behrendt, M.D. Decker, D.J. Burch, P.H. Watson, International variation in the management of infants hospitalized with respiratory syncytial virus, Eur J Pediatr. 157(3) (1998) 215-20.

[12] J.M. Chamberlain, K.M. Patel, M.M. Pollack, Association of emergency department care factors with admission and discharge decisions for pediatric patients, J Pediatr. 149(5) (2006) 644-649.

[13] D.W. Johnson, C. Adair, R. Brant, J. Holmwood, I. Mitchell, Differences in admission rates of children with bronchiolitis by pediatric and general emergency departments, Pediatrics. 110(4) (2002) e49.

[14] M.D. Mallory, D.K. Shay, J. Garrett, W.C. Bordley, Bronchiolitis management preferences and the influence of pulse oximetry and respiratory rate on the decision to admit, Pediatrics. 111(1) (2003) e45-51.

[15] A.C. Plint, D.W. Johnson, N. Wiebe, B. Bulloch, M. Pusic, G. Joubert, et al., Practice variation among pediatric emergency departments in the treatment of bronchiolitis, Acad Emerg Med. 11(4) (2004) 353-60.

[16] A.M. Vogel, D.R. Lennon, J.E. Harding, R.E. Pinnock, D.A. Graham, K. Grimwood, et al., Variations in bronchiolitis management between five New Zealand hospitals: can we do better? J Paediatr Child Health. 39(1) (2003) 40-5.

[17] D.F. Willson, S.D. Horn, J.O. Hendley, R. Smout, J. Gassaway, Effect of practice variation on resource utilization in infants hospitalized for viral lower respiratory illness, Pediatrics. 108(4) (2001) 851-5.

[18] D.F. Willson, J.H. Jiao, J.O. Hendley, L. Donowitz, Invasive monitoring in infants with respiratory syncytial virus infection, J Pediatr. 128(3) (1996) 357-62. 
[19] E.E. Wang, B.J. Law, F.D. Boucher, D. Stephens, J.L. Robinson, S. Dobson, et al., Pediatric Investigators Collaborative Network on Infections in Canada (PICNIC) study of admission and management variation in patients hospitalized with respiratory syncytial viral lower respiratory tract infection, J Pediatr. 129(3) (1996) 390-5.

[20] D.A. Christakis, C.A. Cowan, M.M. Garrison, R. Molteni, E. Marcuse, D.M. Zerr, Variation in inpatient diagnostic testing and management of bronchiolitis, Pediatrics. 115(4) (2005) 878-84.

[21] J.M. Mansbach, S. Clark, N.C. Christopher, F. LoVecchio, S. Kunz, U. Acholonu, et al., Prospective multicenter study of bronchiolitis: predicting safe discharges from the emergency department, Pediatrics. 121(4) (2008) 680-8.

[22] S.C. McBride, V.W. Chiang, D.A. Goldmann, C.P. Landrigan, Preventable adverse events in infants hospitalized with bronchiolitis, Pediatrics. 116(3) (2005) 603-8.

[23] U.R. Kotagal, J.M. Robbins, N.M. Kini, P.J. Schoettker, H.D. Atherton, M.S. Kirschbaum, Impact of a bronchiolitis guideline: a multisite demonstration project, Chest. 121(6) (2002) 1789-97.

[24] P. Walsh, S.J. Rothenberg, S. O’Doherty, H. Hoey, R. Healy, A validated clinical model to predict the need for admission and length of stay in children with acute bronchiolitis, Eur J Emerg Med. 11(5) (2004) 265-72.

[25]P.H. Perlstein, U.R. Kotagal, C. Bolling, R. Steele, P.J. Schoettker, H.D. Atherton, et al., Evaluation of an evidence-based guideline for bronchiolitis, Pediatrics. 104(6) (1999) 1334-41.

[26] P.H. Perlstein, U.R. Kotagal, P.J. Schoettker, H.D. Atherton, M.K. Farrell, W.E. Gerhardt, et al., Sustaining the implementation of an evidence-based guideline for bronchiolitis, Arch Pediatr Adolesc Med. 154(10) (2000) 1001-7.

[27] V. Mittal, C. Darnell, B. Walsh, A. Mehta, M. Badawy, R. Morse, et al., Inpatient bronchiolitis guideline implementation and resource utilization, Pediatrics. 133(3) (2014) e730-7.

[28] A.T. Akenroye, M.N. Baskin, M. Samnaliev, A.M. Stack, Impact of a bronchiolitis guideline on ED resource use and cost: a segmented time-series analysis. Pediatrics. 133(1) (2014) e227-34.

[29] D. Damore, J.M. Mansbach, S. Clark, M. Ramundo, C.A. Jr. Camargo, Prospective multicenter bronchiolitis study: predicting intensive care unit admissions, Acad Emerg Med. 15(10) (2008) 887-94.

[30] M.L. Houben, L. Bont, B. Wilbrink, M.E. Belderbos, J.L. Kimpen, G.H. Visser, et al., Clinical prediction rule for RSV bronchiolitis in healthy newborns: prognostic birth cohort study, Pediatrics. 127(1) (2011) 35-41.

[31] M. Marlais, J. Evans, E. Abrahamson, Clinical predictors of admission in infants with acute bronchiolitis, Arch Dis Child. 96(7) (2011) 648-52. 
[32] A. Norwood, J.M. Mansbach, S. Clark, M. Waseem, C.A. Jr. Camargo, Prospective multicenter study of bronchiolitis: predictors of an unscheduled visit after discharge from the emergency department, Acad Emerg Med. 17(4) (2010) 37682.

[33] E. Rietveld, Y. Vergouwe, E.W. Steyerberg, M.W. Huysman, R. de Groot, H.A. Moll, et al., Hospitalization for respiratory syncytial virus infection in young children: development of a clinical prediction rule, Pediatr Infect Dis J. 25(3) (2006) 201-7.

[34] K.N. Shaw, L.M. Bell, N.H. Sherman, Outpatient assessment of infants with bronchiolitis, Am J Dis Child. 145(2) (1991) $151-5$.

[35] S. Voets, G. van Berlaer, S. Hachimi-Idrissi, Clinical predictors of the severity of bronchiolitis, Eur J Emerg Med. 13(3) (2006) 134-8.

[36] P. Walsh, P. Cunningham, S.J. Rothenberg, S. O’Doherty, H. Hoey, R. Healy, An artificial neural network ensemble to predict disposition and length of stay in children presenting with bronchiolitis, Eur J Emerg Med. 11(5) (2004) 259-64.

[37] M.C. Weisgerber, P.S. Lye, S.H. Li, D. Bakalarski, R. Gedeit, P. Simpson, et al., Factors predicting prolonged hospital stay for infants with bronchiolitis, J Hosp Med. 6(5) (2011) 264-70.

[38]E.W. Steyerberg, Clinical Prediction Models: A Practical Approach to Development, Validation, and Updating, Springer, New York, NY, 2009.

[39] M. Kuhn, K. Johnson, Applied Predictive Modeling, Springer, New York, NY, 2013.

[40]P. Prodhan, S. Sharoor-Karni, J. Lin, N. Noviski, Predictors of respiratory failure among previously healthy children with respiratory syncytial virus infection, Am J Emerg Med. 29(2) (2011) 168-73.

[41] L. Destino, M.C. Weisgerber, P. Soung, D. Bakalarski, K. Yan, R. Rehborg, et al., Validity of respiratory scores in bronchiolitis, Hosp Pediatr. 2(4) (2012) 202-9.

[42] F.R. Laham, A.A. Trott, B.L. Bennett, C.A. Kozinetz, A.M. Jewell, R.P. Garofalo, et al., LDH concentration in nasalwash fluid as a biochemical predictor of bronchiolitis severity, Pediatrics. 125(2) (2010) e225-33.

[43] H.M. Corneli, J.J. Zorc, R. Holubkov, J.S. Bregstein, K.M. Brown, P. Mahajan, et al., Bronchiolitis: clinical characteristics associated with hospitalization and length of stay, Pediatr Emerg Care. 28(2) (2012) 99-103.

[44] M.A. Al-Shehri, A. Sadeq, K. Quli, Bronchiolitis in Abha, Southwest Saudi Arabia: viral etiology and predictors for hospital admission, West Afr J Med. 24(4) (2005) 299-304. 
[45] J.M. Mansbach, P.A. Piedra, F.R. Laham, A.J. McAdam, S. Clark, A.F. Sullivan, et al., Nasopharyngeal lactate dehydrogenase concentrations predict bronchiolitis severity in a prospective multicenter emergency department study, Pediatr Infect Dis J. 31(7) (2012) 767-9.

[46] V.J. Wang, C.S. Cavagnaro, S. Clark, C.A. Jr Camargo, J.M. Mansbach, Altitude and environmental climate effects on bronchiolitis severity among children presenting to the emergency department, J Environ Health. 75(3) (2012) 8-15.

[47] M.S. Nascimento, A.V. Souza, A.V. Ferreira, J.C. Rodrigues, S. Abramovici, L.V. Silva Filho, High rate of viral identification and coinfections in infants with acute bronchiolitis, Clinics (Sao Paulo). 65(11) (2010) 1133-7.

[48] D.N. Marcone, A. Ellis, C. Videla, J. Ekstrom, C. Ricarte, G. Carballal, et al., Viral etiology of acute respiratory infections in hospitalized and outpatient children in Buenos Aires, Argentina, Pediatr Infect Dis J. 32(3) (2013) e105-10.

[49] R. Somech, G. Tal, E. Gilad, A. Mandelberg, A. Tal, I. Dalal, Epidemiologic, socioeconomic, and clinical factors associated with severity of respiratory syncytial virus infection in previously healthy infants, Clin Pediatr (Phila). 45(7) (2006) 621-7.

[50]E.E. Wang, R.A. Milner, L. Navas, H. Maj, Observer agreement for respiratory signs and oximetry in infants hospitalized with lower respiratory infections, Am Rev Respir Dis. 145(1) (1992) 106-9.

[51] J.L. Wiler, M.A. Ross, A.A. Ginde, National study of emergency department observation services, Acad Emerg Med. 18(9) (2011) 959-65.

[52]E.R. Alpern, D.P. Calello, R. Windreich, K. Osterhoudt, K.N. Shaw, Utilization and unexpected hospitalization rates of a pediatric emergency department 23-hour observation unit, Pediatr Emerg Care. 24(9) (2008) 589-94.

[53] D.R. Sandweiss, H.M. Corneli, H.A. Kadish, Barriers to discharge from a 24-hour observation unit for children with bronchiolitis, Pediatr Emerg Care. 26(12) (2010) 892-6.

[54] S. Yusuf, A.C. Caviness, A.O. Adekunle-Ojo, Risk factors for admission in children with bronchiolitis from pediatric emergency department observation unit, Pediatr Emerg Care. 28(11) (2012) 1132-5.

[55] A.M. Brooks, J.T. McBride, K.M. McConnochie, M. Aviram, C. Long, C.B. Hall, Predicting deterioration in previously healthy infants hospitalized with respiratory syncytial virus infection, Pediatrics. 104(3 Pt 1) (1999) 463-7.

[56] A. Mandelberg, G. Tal, L. Naugolny, K. Cesar, A. Oron, S. Houri, et al., Lipopolysaccharide hyporesponsiveness as a risk factor for intensive care unit hospitalization in infants with respiratory syncitial virus bronchiolitis, Clin Exp Immunol. 144(1) (2006) 48-52. 
[57] C.G. García, R. Bhore, A. Soriano-Fallas, M. Trost, R. Chason, O. Ramilo, et al., Risk factors in children hospitalized with RSV bronchiolitis versus non-RSV bronchiolitis, Pediatrics. 126(6) (2010) e1453-60.

[58] D. Hervás, J. Reina, A. Yañez, J.M. del Valle, J. Figuerola, J.A. Hervás, Epidemiology of hospitalization for acute bronchiolitis in children: differences between RSV and non-RSV bronchiolitis, Eur J Clin Microbiol Infect Dis. 31(8) (2012) 1975-81.

[59] N. Richard, F. Komurian-Pradel, E. Javouhey, M. Perret, A. Rajoharison, A. Bagnaud, et al., The impact of dual viral infection in infants admitted to a pediatric intensive care unit associated with severe bronchiolitis, Pediatr Infect Dis $J$. 27(3) (2008) 213-7.

[60] J.T. Verger, E.E. Verger, Respiratory syncytial virus bronchiolitis in children, Crit Care Nurs Clin North Am. 24(4) (2012) $555-72$.

[61] G.F. Langley, L.J. Anderson, Epidemiology and prevention of respiratory syncytial virus infections among infants and young children, Pediatr Infect Dis J. 30(6) (2011) 510-7.

[62] Y. Aujard, B. Fauroux, Risk factors for severe respiratory syncytial virus infection in infants, Respir Med. 96 Suppl B (2002) S9-14.

[63]C.M. El Saleeby, R. Li, G.W. Somes, M.K. Dahmer, M.W. Quasney, J.P. DeVincenzo, Surfactant protein A2 polymorphisms and disease severity in a respiratory syncytial virus-infected population, J Pediatr. 156(3) (2010) 409-14.

[64] K. Purcell, J. Fergie, Driscoll Children's Hospital respiratory syncytial virus database: risk factors, treatment and hospital course in 3308 infants and young children, 1991 to 2002, Pediatr Infect Dis J. 23(5) (2004) 418-23.

[65] H. Chi, I.S. Chang, F.Y. Tsai, L.M. Huang, P.L. Shao, N.C. Chiu, et al., Epidemiological study of hospitalization associated with respiratory syncytial virus infection in Taiwanese children between 2004 and 2007, J Formos Med Assoc. $110(6)(2011) 388-96$.

[66] M. Dotan, L. Ashkenazi-Hoffnung, Z. Samra, G. Livni, H. Yarden-Bilavsky, J. Amir, et al., Hospitalization for respiratory syncytial virus bronchiolitis and disease severity in twins, Isr Med Assoc J. 15(11) (2013) 701-4.

[67] A.A. El Kholy, N.A. Mostafa, S.A. El-Sherbini, A.A. Ali, R.I. Ismail, R.I. Magdy, et al., Morbidity and outcome of severe respiratory syncytial virus infection, Pediatr Int. 55(3) (2013) 283-8.

[68] K.L. Hon, T.F. Leung, W.Y. Cheng, N.M. Ko, W.K. Tang, W.W. Wong, et al., Respiratory syncytial virus morbidity, premorbid factors, seasonality, and implications for prophylaxis, J Crit Care. 27(5) (2012) 464-8. 
[69] J.M. Mansbach, P.A. Piedra, M.D. Stevenson, A.F. Sullivan, T.F. Forgey, S. Clark, et al., Prospective multicenter study of children with bronchiolitis requiring mechanical ventilation, Pediatrics. 130(3) (2012) e492-500.

[70] B. Al-Shawwa, N. Al-Huniti, M. Weinberger, M. Abu-Hasan, Clinical and therapeutic variables influencing hospitalisation for bronchiolitis in a community-based paediatric group practice, Prim Care Respir J. 16(2) (2007) 93-7.

[71] A.R. Schroeder, J.M. Mansbach, M. Stevenson, C.G. Macias, E.S. Fisher, B. Barcega, et al., Apnea in children hospitalized with bronchiolitis, Pediatrics. 132(5) (2013) e1194-201.

[72] S. Ralston, V. Hill, Incidence of apnea in infants hospitalized with respiratory syncytial virus bronchiolitis: a systematic review, J Pediatr. 155(5) (2009) 728-33.

[73] M.C. Kneyber, A.H. Brandenburg, R. de Groot, K.F. Joosten, P.H. Rothbarth, A. Ott, et al., Risk factors for respiratory syncytial virus associated apnoea, Eur J Pediatr. 157(4) (1998) 331-5.

[74] O. Schiller, I. Levy, U. Pollak, G. Kadmon, E. Nahum, T. Schonfeld, Central apnoeas in infants with bronchiolitis admitted to the paediatric intensive care unit, Acta Paediatr. 100(2) (2011) 216-9.

[75] B.M. Willwerth, M.B. Harper, D.S. Greenes, Identifying hospitalized infants who have bronchiolitis and are at high risk for apnea, Ann Emerg Med. 48(4) (2006) 441-7.

[76] J. Evans, M. Marlais, E. Abrahamson, Clinical predictors of nasal continuous positive airway pressure requirement in acute bronchiolitis, Pediatr Pulmonol. 47(4) (2012) 381-5.

[77] C. Milési, S. Matecki, S. Jaber, T. Mura, A. Jacquot, O. Pidoux, et al., $6 \mathrm{cmH} 2 \mathrm{O}$ continuous positive airway pressure versus conventional oxygen therapy in severe viral bronchiolitis: a randomized trial, Pediatr Pulmonol. 48(1) (2013) 4551.

[78] J. Mayordomo-Colunga, A. Medina, C. Rey, J.J. Díaz, A. Concha, M. Los Arcos, et al., Predictive factors of non invasive ventilation failure in critically ill children: a prospective epidemiological study, Intensive Care Med. 35(3) (2009) 527-36.

[79]A. Najaf-Zadeh, F. Leclerc, Noninvasive positive pressure ventilation for acute respiratory failure in children: a concise review, Ann Intensive Care. 1 (2011) 15.

[80] P.A. Abboud, P.J. Roth, C.L. Skiles, A. Stolfi, M.E. Rowin, Predictors of failure in infants with viral bronchiolitis treated with high-flow, high-humidity nasal cannula therapy, Pediatr Crit Care Med. 13(6) (2012) e343-9.

[81] E. Javouhey, A. Barats, N. Richard, D. Stamm, D. Floret, Non-invasive ventilation as primary ventilatory support for infants with severe bronchiolitis, Intensive Care Med. 34(9) (2008) 1608-14. 
[82] V. Bernet, M.I. Hug, B. Frey, Predictive factors for the success of noninvasive mask ventilation in infants and children with acute respiratory failure, Pediatr Crit Care Med. 6(6) (2005) 660-4.

[83] G.S. Kelly, H.K. Simon, J.J. Sturm, High-flow nasal cannula use in children with respiratory distress in the emergency department: predicting the need for subsequent intubation, Pediatr Emerg Care. 29(8) (2013) 888-92.

[84] Y. Cavari, S. Sofer, U. Rozovski, I. Lazar, Non invasive positive pressure ventilation in infants with respiratory failure, Pediatr Pulmonol. 47(10) (2012) 1019-25.

[85] S.S. Ganu, A. Gautam, B. Wilkins, J. Egan, Increase in use of non-invasive ventilation for infants with severe bronchiolitis is associated with decline in intubation rates over a decade, Intensive Care Med. 38(7) (2012) 1177-83.

[86] M.G. Semple, D.C. Taylor-Robinson, S. Lane, R.L. Smyth, Household tobacco smoke and admission weight predict severe bronchiolitis in infants independent of deprivation: prospective cohort study, PLoS One. 6(7) (2011) e22425.

[87] T.V. Mai, A.M. Selby, J.M. Simpson, D. Isaacs, Use of simple clinical parameters to assess severity of bronchiolitis, $J$ Paediatr Child Health. 31(5) (1995) 465-8.

[88] G.B. McCallum, P.S. Morris, C.C. Wilson, L.A. Versteegh, L.M. Ward, M.D. Chatfield, et al., Severity scoring systems: are they internally valid, reliable and predictive of oxygen use in children with acute bronchiolitis? Pediatr Pulmonol. 48(8) (2013) 797-803.

[89] L. Bont, J.L. Kimpen, Immunological mechanisms of severe respiratory syncytial virus bronchiolitis, Intensive Care Med. 28(5) (2002) 616-21.

[90] M.H. Lebel, M. Gauthier, J. Lacroix, E. Rousseau, M. Buithieu, Respiratory failure and mechanical ventilation in severe bronchiolitis, Arch Dis Child. 64(10) (1989) 1431-7.

[91] P.W. Chan, A.Y. Goh, L.C. Lum, Severe bronchiolitis in Malaysian children, J Trop Pediatr. 46(4) (2000) 234-6.

[92] J.P. DeVincenzo, C.M. El Saleeby, A.J. Bush, Respiratory syncytial virus load predicts disease severity in previously healthy infants, J Infect Dis. 191(11) (2005) 1861-8.

[93]H.K. Brand, G. Ferwerda, F. Preijers, R. de Groot, C. Neeleman, F.J. Staal, et al., CD4+ T-cell counts and interleukin-8 and CCL-5 plasma concentrations discriminate disease severity in children with RSV infection, Pediatr Res. 73(2) (2013) 187-93.

[94] L. Bont, C.J. Heijnen, A. Kavelaars, W.M. van Aalderen, F. Brus, J.M. Draaisma, et al., Local interferon- $\gamma$ levels during respiratory syncytial virus lower respiratory tract infection are associated with disease severity, J Infect Dis. 184(3) (2001) $355-8$. 
[95] J.A. Moynihan, L. Brown, R. Sehra, P.A. Checchia, Cardiac troponin I as a predictor of respiratory failure in children hospitalized with respiratory syncytial virus (RSV) infections: a pilot study, Am J Emerg Med. 21(6) (2003) 479-82.

[96] P. Zachariah, M. Ruttenber, E.A. Simões, Hospitalizations due to respiratory syncytial virus in children with congenital malformations, Pediatr Infect Dis J. 30(5) (2011) 442-5.

[97] D. van Beek, B. Paes, L. Bont, Increased risk of RSV infection in children with Down's syndrome: clinical implementation of prophylaxis in the European Union, Clin Dev Immunol. 2013 (2013) 801581.

[98] P. Prodhan, S.J. Westra, J. Lin, S. Karni-Sharoor, S. Regan, N. Noviski, Chest radiological patterns predict the duration of mechanical ventilation in children with RSV infection, Pediatr Radiol. 39(2) (2009) 117-23.

[99] C. Flamant, F. Hallalel, P. Nolent, J.Y. Chevalier, S. Renolleau, Severe respiratory syncytial virus bronchiolitis in children: from short mechanical ventilation to extracorporeal membrane oxygenation, Eur J Pediatr. 164(2) (2005) 93-8.

[100] J.C. Hsu, Y.F. Chen, Y.C. Du, Y.F. Huang, X. Jiang, T. Chen, Design of a clinical decision support system for determining ventilator weaning using support sector machine, International Journal of Innovative Computing, Information and Control 8(1B) (2012) 933-952.

[101] J.J. Stambouly, L.L. McLaughlin, F.S. Mandel, R.A. Boxer, Complications of care in a pediatric intensive care unit: a prospective study, Intensive Care Med. 22(10) (1996) 1098-104.

[102] P.J. Thompson, A. Greenough, M.F. Hird, J. Philpott-Howard, H.R. Gamsu, Nosocomial bacterial infections in very low birth weight infants, Eur J Pediatr. 151(6) (1992) 451-4.

[103] S.K. Epstein, R.L. Ciubotaru, J.B. Wong, Effect of failed extubation on the outcome of mechanical ventilation, Chest. $112(1)(1997) 186-92$.

[104] N. Khan, A. Brown, S.T. Venkataraman, Predictors of extubation success and failure in mechanically ventilated infants and children, Crit Care Med. 24(9) (1996) 1568-79.

[105] S.C. Kurachek, C.J. Newth, M.W. Quasney, T. Rice, R.C. Sachdeva, N.R. Patel, et al., Extubation failure in pediatric intensive care: a multiple-center study of risk factors and outcomes, Crit Care Med. 31(11) (2003) 2657-64.

[106] A.G. Randolph, D. Wypij, S.T. Venkataraman, J.H. Hanson, R.G. Gedeit, K.L. Meert, et al., Effect of mechanical ventilator weaning protocols on respiratory outcomes in infants and children: a randomized controlled trial, JAMA. 288(20) (2002) 2561-8.

[107] C. Johnston, W.B. de Carvalho, J. Piva, P.C. Garcia, M.C. Fonseca, Risk factors for extubation failure in infants with severe acute bronchiolitis, Respir Care. 55(3) (2010) 328-33. 
[108] T.I. Manczur, A. Greenough, D. Pryor, G.F. Rafferty, Comparison of predictors of extubation from mechanical ventilation in children, Pediatr Crit Care Med. 1(1) (2000) 28-32.

[109] M. Mueller, J.S. Almeida, R. Stanislaus, C.L. Wagner, Can machine learning methods predict extubation outcome in premature infants as well as clinicians? J Neonatal Biol 2 (2013) 118.

[110] J.C. Hsu, Y.F. Chen, W.S. Chung, T.H. Tan, T. Chen, J.Y. Chiang, Clinical verification of a clinical decision support system for ventilator weaning, BioMedical Engineering OnLine 12(Suppl 1) (2013) S4.

[111] K. Purcell, J. Fergie, Lack of usefulness of an abnormal white blood cell count for predicting a concurrent serious bacterial infection in infants and young children hospitalized with respiratory syncytial virus lower respiratory tract infection, Pediatr Infect Dis J. 26(4) (2007) 311-5.

[112] J.A. Antonow, K. Hansen, C.A. McKinstry, C.L. Byington, Sepsis evaluations in hospitalized infants with bronchiolitis, Pediatr Infect Dis J. 17(3) (1998) 231-6.

[113] E. Bilavsky, D.S. Shouval, H. Yarden-Bilavsky, N. Fisch, S. Ashkenazi, J. Amir, A prospective study of the risk for serious bacterial infections in hospitalized febrile infants with or without bronchiolitis, Pediatr Infect Dis J. 27(3) (2008) 269-70.

[114] K. Purcell, J. Fergie, Concurrent serious bacterial infections in 2396 infants and children hospitalized with respiratory syncytial virus lower respiratory tract infections, Arch Pediatr Adolesc Med. 156(4) (2002) 322-4.

[115] P. Bloomfield, D. Dalton, A. Karleka, A. Kesson, G. Duncan, D. Isaacs, Bacteraemia and antibiotic use in respiratory syncytial virus infections, Arch Dis Child. 89(4) (2004) 363-7.

[116] M.C. Kneyber, K.G. Moons, R. de Groot, H.A. Moll, Predictors of a normal chest x-ray in respiratory syncytial virus infection, Pediatr Pulmonol. 31(4) (2001) 277-83.

[117] S. Schuh, A. Lalani, U. Allen, D. Manson, P. Babyn, D. Stephens, et al., Evaluation of the utility of radiography in acute bronchiolitis, J Pediatr. 150(4) (2007) 429-33.

[118] S.M. Meystre, G.K. Savova, K.C. Kipper-Schuler, J.F. Hurdle, Extracting information from textual documents in the electronic health record: a review of recent research, Yearb Med Inform. (2008) 128-144.

[119] S. Dublin, E. Baldwin, R.L. Walker, L.M. Christensen, P.J. Haug, M.L. Jackson, et al., Natural language processing to identify pneumonia from radiology reports, Pharmacoepidemiol Drug Saf. 22(8) (2013) 834-41.

[120] Y. Durani, M.J. Friedman, M.W. Attia, Clinical predictors of respiratory syncytial virus infection in children, Pediatr Int. 50(3) (2008) 352-5. 
[121] S. Jhawar, Severe bronchiolitis in children, Clin Rev Allergy Immunol. 25(3) (2003) 249-57.

[122] D. Isaacs, H. Dickson, C. O'Callaghan, R. Sheaves, A. Winter, E.R. Moxon, Handwashing and cohorting in prevention of hospital acquired infections with respiratory syncytial virus, Arch Dis Child. 66(2) (1991) 227-31.

[123] D.A. Levine, S.L. Platt, P.S. Dayan, C.G. Macias, J.J. Zorc, W. Krief, et al., Risk of serious bacterial infection in young febrile infants with respiratory syncytial virus infections, Pediatrics. 113(6) (2004) 1728-34.

[124] M.O. Titus, S.W. Wright, Prevalence of serious bacterial infections in febrile infants with respiratory syncytial virus infection, Pediatrics. 112(2) (2003) 282-4.

[125] A.G. Randolph, L. Reder, J.A. Englund, Risk of bacterial infection in previously healthy respiratory syncytial virusinfected young children admitted to the intensive care unit, Pediatr Infect Dis J. 23(11) (2004) 990-4.

[126] A.G. Riccetto, J.D. Ribeiro, M.T. Silva, R.S. Almeida, C.W. Arns, E.C. Baracat, Respiratory syncytial virus (RSV) in infants hospitalized for acute lower respiratory tract disease: incidence and associated risks, Braz J Infect Dis. 10(5) (2006) $357-61$.

[127] F.W. Moler, S.E. Ohmit, Severity of illness models for respiratory syncytial virus-associated hospitalization, Am J Respir Crit Care Med. 159(4 Pt 1) (1999) 1234-40.

[128] M.C. Kneyber, K.G. Moons, R. de Groot, H.A. Moll, Prediction of duration of hospitalization in respiratory syncytial virus infection, Pediatr Pulmonol. 33(6) (2002) 453-7.

[129] C.M. El Saleeby, A.J. Bush, L.M. Harrison, J.A. Aitken, J.P. Devincenzo, Respiratory syncytial virus load, viral dynamics, and disease severity in previously healthy naturally infected children, J Infect Dis. 204(7) (2011) 996-1002.

[130] J.A. McMillan, D.A. Tristram, L.B. Weiner, A.P. Higgins, C. Sandstrom, R. Brandon, Prediction of the duration of hospitalization in patients with respiratory syncytial virus infection: use of clinical parameters, Pediatrics. 81(1) (1988) 22-6.

[131] K. Kristensen, T. Hjuler, H. Ravn, E.A. Simões, L.G. Stensballe, Chronic diseases, chromosomal abnormalities, and congenital malformations as risk factors for respiratory syncytial virus hospitalization: a population-based cohort study, Clin Infect Dis. 54(6) (2012) 810-7.

[132] S. Broughton, A. Roberts, G. Fox, E. Pollina, M. Zuckerman, S. Chaudhry, et al., Prospective study of healthcare utilisation and respiratory morbidity due to RSV infection in prematurely born infants, Thorax. 60(12) (2005) 1039-44.

[133] K.S. Kott, B.H. Salt, R.J. McDonald, S. Jhawar, J.M. Bric, J.P. Joad, Effect of secondhand cigarette smoke, RSV bronchiolitis and parental asthma on urinary cysteinyl LTE4, Pediatr Pulmonol. 43(8) (2008) 760-6. 
[134] C. Mella, M.C. Suarez-Arrabal, S. Lopez, J. Stephens, S. Fernandez, M.W. Hall, et al., Innate immune dysfunction is associated with enhanced disease severity in infants with severe respiratory syncytial virus bronchiolitis, $J$ Infect Dis. 207(4) (2013) 564-73.

[135] E. Rietveld, H.C. De Jonge, J.J. Polder, Y. Vergouwe, H.J. Veeze, H.A. Moll, et al., Anticipated costs of hospitalization for respiratory syncytial virus infection in young children at risk, Pediatr Infect Dis J. 23(6) (2004) 523-9.

[136] E.S. Fieldston, I. Zaniletti, M. Hall, J.D. Colvin, L. Gottlieb, M.L. Macy, et al., Community household income and resource utilization for common inpatient pediatric conditions, Pediatrics. 132(6) (2013) e1592-601.

[137] The IMpact-RSV Study Group, Palivizumab, a humanized respiratory syncytial virus monoclonal antibody, reduces hospitalization from respiratory syncytial virus infection in high-risk infants, Pediatrics. 102(3 Pt 1) (1998) 531-7.

[138] X. Carbonell-Estrany, E.A. Simões, J.R. Fullarton, C. Ferdynus, J.B. Gouyon; European RSV Risk Factor Study Group, Validation of a model to predict hospitalization due to RSV of infants born at 33-35 weeks' gestation, J Perinat Med. 38(4) (2010) 411-7.

[139] K.A. Smart, K.L. Lanctôt, B.A. Paes, The cost effectiveness of palivizumab: a systematic review of the evidence, $J$ Med Econ. 13(3) (2010) 453-63.

[140] X. Carbonell-Estrany, L. Bont, G. Doering, J.B. Gouyon, M. Lanari, Clinical relevance of prevention of respiratory syncytial virus lower respiratory tract infection in preterm infants born between 33 and 35 weeks gestational age, Eur J Clin Microbiol Infect Dis. 27(10) (2008) 891-9.

[141] J.M. Hussman, A. Li, B. Paes, K.L. Lanctôt, A review of cost-effectiveness of palivizumab for respiratory syncytial virus, Expert Rev Pharmacoecon Outcomes Res. 12(5) (2012) 553-67.

[142] J. McCormick, R. Tubman, Readmission with respiratory syncytial virus (RSV) infection among graduates from a neonatal intensive care unit, Pediatr Pulmonol. 34(4) (2002) 262-6.

[143] B. Paes, S. Steele, M. Janes, J. Pinelli, Risk-scoring tool for respiratory syncytial virus prophylaxis in premature infants born at 33-35 completed weeks' gestational age in Canada, Curr Med Res Opin. 25(7) (2009) 1585-91.

[144] E.A. Simões, X. Carbonell-Estrany, J.R. Fullarton, J.G. Liese, J. Figueras-Aloy, G. Doering, et al., A predictive model for respiratory syncytial virus (RSV) hospitalisation of premature infants born at 33-35 weeks of gestational age, based on data from the Spanish FLIP Study, Respir Res. 9 (2008) 78. 
[145] B.J. Law, J.M. Langley, U. Allen, B. Paes, D.S. Lee, I. Mitchell, et al., The Pediatric Investigators Collaborative Network on Infections in Canada study of predictors of hospitalization for respiratory syncytial virus infection for infants born at 33 through 35 completed weeks of gestation, Pediatr Infect Dis J. 23(9) (2004) 806-14.

[146] J.S. Sampalis, J. Langley, X. Carbonell-Estrany, B. Paes, K. O’Brien, U. Allen, et al., Development and validation of a risk scoring tool to predict respiratory syncytial virus hospitalization in premature infants born at 33 through 35 completed weeks of gestation, Med Decis Making. 28(4) (2008) 471-80.

[147] J.S. Sampalis, Morbidity and mortality after RSV-associated hospitalizations among premature Canadian infants, $J$ Pediatr. 143(5 Suppl) (2003) S150-6.

[148] M.O. Blanken, H. Koffijberg, E.E. Nibbelke, M.M. Rovers, L. Bont; Dutch RSV Neonatal Network, Prospective validation of a prognostic model for respiratory syncytial virus bronchiolitis in late preterm infants: a multicenter birth cohort study, PLoS One. 8(3) (2013) e59161.

[149] E.A. Simões, X. Carbonell-Estrany, J.R. Fullarton, G.A. Rossi, I. Barberi, M. Lanari, et al., European risk factors’ model to predict hospitalization of premature infants born 33-35 weeks' gestational age with respiratory syncytial virus: validation with Italian data, J Matern Fetal Neonatal Med. 24(1) (2011) 152-7.

[150] L.G. Stensballe, J.R. Fullarton, X. Carbonell-Estrany, E.A. Simões, Population based external validation of a European predictive model for respiratory syncytial virus hospitalization of premature infants born 33 to 35 weeks of gestational age, Pediatr Infect Dis J. 29(4) (2010) 374-6.

[151] B. Paes, M. Cole, A. Latchman, J. Pinelli, Predictive value of the respiratory syncytial virus risk-scoring tool in the term infant in Canada, Curr Med Res Opin. 25(9) (2009) 2191-6.

[152] J.A. Choudhuri, L.G. Ogden, A.J. Ruttenber, D.S. Thomas, J.K. Todd, E.A. Simoes, Effect of altitude on hospitalizations for respiratory syncytial virus infection, Pediatrics. 117(2) (2006) 349-56.

[153] G.A. Rossi, M.C. Medici, M.C. Arcangeletti, M. Lanari, R. Merolla, U.D. Paparatti, et al., Risk factors for severe RSVinduced lower respiratory tract infection over four consecutive epidemics, Eur J Pediatr. 166(12) (2007) 1267-72.

[154] C.A. Reeve, J.S. Whitehall, P.G. Buettner, R. Norton, D.M. Reeve, F. Francis, Predicting respiratory syncytial virus hospitalisation in Australian children, J Paediatr Child Health. 42(5) (2006) 248-52.

[155] L.R. Bulkow, R.J. Singleton, C. DeByle, K. Miernyk, G. Redding, K.B. Hummel, et al., Risk factors for hospitalization with lower respiratory tract infections in children in rural Alaska, Pediatrics. 129(5) (2012) e1220-7. 
[156] T. Goetghebuer, D. Kwiatkowski, A. Thomson, J. Hull, Familial susceptibility to severe respiratory infection in early life, Pediatr Pulmonol. 38(4) (2004) 321-8.

[157] B.J. Law, X. Carbonell-Estrany, E.A. Simoes, An update on respiratory syncytial virus epidemiology: a developed country perspective, Respir Med. 96 Suppl B (2002) S1-7.

[158] J. Figueras-Aloy, X. Carbonell-Estrany, J. Quero; IRIS Study Group, Case-control study of the risk factors linked to respiratory syncytial virus infection requiring hospitalization in premature infants born at a gestational age of 33-35 weeks in Spain, Pediatr Infect Dis J. 23(9) (2004) 815-20.

[159] G. Cilla, A. Sarasua, M. Montes, N. Arostegui, D. Vicente, E. Pérez-Yarza, et al., Risk factors for hospitalization due to respiratory syncytial virus infection among infants in the Basque Country, Spain, Epidemiol Infect. 134(3) (2006) 506-13.

[160] E.K. Miller, J.V. Williams, T. Gebretsadik, K.N. Carroll, W.D. Dupont, Y.A. Mohamed, et al., Host and viral factors associated with severity of human rhinovirus-associated infant respiratory tract illness, J Allergy Clin Immunol. 127(4) (2011) 883-91.

[161] P. Pezzotti, J. Mantovani, N. Benincori, E. Mucchino, D. Di Lallo, Incidence and risk factors of hospitalization for bronchiolitis in preterm children: a retrospective longitudinal study in Italy, BMC Pediatr. 9 (2009) 56.

[162] J.G. Liese, E. Grill, B. Fischer, I. Roeckl-Wiedmann, D. Carr, B.H. Belohradsky, Incidence and risk factors of respiratory syncytial virus-related hospitalizations in premature infants in Germany, Eur J Pediatr. 162(4) (2003) 230-6.

[163] R. Janssen, L. Bont, C.L. Siezen, H.M. Hodemaekers, M.J. Ermers, G. Doornbos, et al., Genetic susceptibility to respiratory syncytial virus bronchiolitis is predominantly associated with innate immune genes, J Infect Dis. 196(6) (2007) 826-34.

[164] L. Jansson, P. Nilsson, M. Olsson, Socioeconomic environmental factors and hospitalization for acute bronchiolitis during infancy, Acta Paediatr. 91(3) (2002) 335-8.

[165] K.N. Carroll, T. Gebretsadik, M.R. Griffin, W.D. Dupont, E.F. Mitchel, P. Wu, et al., Maternal asthma and maternal smoking are associated with increased risk of bronchiolitis during infancy, Pediatrics. 119(6) (2007) 1104-12.

[166] L.G. Stensballe, K. Kristensen, E.A. Simoes, H. Jensen, J. Nielsen, C.S. Benn, et al., Atopic disposition, wheezing, and subsequent respiratory syncytial virus hospitalization in Danish children younger than 18 months: a nested case-control study, Pediatrics. 118(5) (2006) e1360-8.

[167] E.A. Simoes, S.J. King, M.V. Lehr, J.R. Groothuis, Preterm twins and triplets. A high-risk group for severe respiratory syncytial virus infection, Am J Dis Child. 147(3) (1993) 303-6. 
[168] M.W. Weber, P. Milligan, S. Hilton, G. Lahai, H. Whittle, E.K. Mulholland, et al., Risk factors for severe respiratory syncytial virus infection leading to hospital admission in children in the Western Region of The Gambia, Int J Epidemiol. 28(1) (1999) 157-62.

[169] C. Karr, T. Lumley, A. Schreuder, R. Davis, T. Larson, B. Ritz, et al., Effects of subchronic and chronic exposure to ambient air pollutants on infant bronchiolitis, Am J Epidemiol. 165(5) (2007) 553-60.

[170] S.M. Szabo, K.L. Gooch, E.E. Korol, P. Bradt, P. Vo, A.R. Levy, Respiratory distress syndrome at birth is a risk factor for hospitalization for lower respiratory tract infections in infancy, Pediatr Infect Dis J. 31(12) (2012) 1245-51.

[171] H.C. Moore, N. de Klerk, P. Holt, P.C. Richmond, D. Lehmann, Hospitalisation for bronchiolitis in infants is more common after elective caesarean delivery, Arch Dis Child. 97(5) (2012) 410-4.

[172] A. Eick, R. Karron, J. Shaw, B. Thumar, R. Reid, M. Santosham, et al., The role of neutralizing antibodies in protection of American Indian infants against respiratory syncytial virus disease, Pediatr Infect Dis J. 27(3) (2008) 207-12.

[173] T.L. Kresfelder, R. Janssen, L. Bont, M. Pretorius, M. Venter, Confirmation of an association between single nucleotide polymorphisms in the VDR gene with respiratory syncytial virus related disease in South African children, $J$ Med Virol. 83(10) (2011) 1834-40.

[174] J. Moyes, C. Cohen, M. Pretorius, M. Groome, A. von Gottberg, N. Wolter, et al., Epidemiology of respiratory syncytial virus-associated acute lower respiratory tract infection hospitalizations among HIV-infected and HIV-uninfected South African children, 2010-2011, J Infect Dis. 208 Suppl 3 (2013) S217-26.

[175] H.W. Park, B.S. Lee, A.R. Kim, H.S. Yoon, B.I. Kim, E.S. Song, et al., Epidemiology of respiratory syncytial virus infection in infants born at less than thirty-five weeks of gestational age, Pediatr Infect Dis J. 31(8) (2012) e99-104.

[176] S. Joffe, G.J. Escobar, S.B. Black, M.A. Armstrong, T.A. Lieu, Rehospitalization for respiratory syncytial virus among premature infants, Pediatrics. 104(4 Pt 1) (1999) 894-9.

[177] K. Kristensen, L.G. Stensballe, J. Bjerre, D. Roth, N. Fisker, T. Kongstad, et al., Risk factors for respiratory syncytial virus hospitalisation in children with heart disease, Arch Dis Child. 94(10) (2009) 785-9.

[178] E. Vardas, D. Blaauw, J. McAnerney, The epidemiology of respiratory syncytial virus (RSV) infections in South African children, S Afr Med J. 89(10) (1999) 1079-84.

[179] X. Carbonell-Estrany, J. Figueras-Aloy, B.J. Law; Infección Respiratoria Infantil por Virus Respiratorio Sincitial Study Group; Pediatric Investigators Collaborative Network on Infections in Canada Study Group, Identifying risk factors for 
severe respiratory syncytial virus among infants born after 33 through 35 completed weeks of gestation: different methodologies yield consistent findings, Pediatr Infect Dis J. 23(11 Suppl) (2004) S193-201.

[180] L.G. Stensballe, H. Ravn, K. Kristensen, K. Agerskov, T. Meakins, P. Aaby, et al., Respiratory syncytial virus neutralizing antibodies in cord blood, respiratory syncytial virus hospitalization, and recurrent wheeze, J Allergy Clin Immunol. 123(2) (2009) 398-403.

[181] H.E. Nielsen, V. Siersma, S. Andersen, B. Gahrn-Hansen, C.H. Mordhorst, B. Nørgaard-Pedersen, et al., Respiratory syncytial virus infection - risk factors for hospital admission: a case-control study, Acta Paediatr. 92(11) (2003) 1314-21.

[182] G. Doering, W. Gusenleitner, B.H. Belohradsky, S. Burdach, B. Resch, J.G. Liese, The risk of respiratory syncytial virusrelated hospitalizations in preterm infants of 29 to 35 weeks' gestational age, Pediatr Infect Dis J. 25(12) (2006) 1188-90.

[183] R.C. Sr. Welliver, Temperature, humidity, and ultraviolet B radiation predict community respiratory syncytial virus activity, Pediatr Infect Dis J. 26(11 Suppl) (2007) S29-35.

[184] N.A. Walton, M.R. Poynton, P.H. Gesteland, C. Maloney, C. Staes, J.C. Facelli, Predicting the start week of respiratory syncytial virus outbreaks using real time weather variables, BMC Med Inform Decis Mak. 10 (2010) 68.

[185] I.M. Birkhaug, C.S. Inchley, G. Aamodt, G. Ånestad, W. Nystad, B. Nakstad, Infectious burden of respiratory syncytial virus in relation to time of birth modifies the risk of lower respiratory tract infection in infancy: the Norwegian Mother and Child Cohort, Pediatr Infect Dis J. 32(6) (2013) e235-41.

[186] D.L. Langkamp, S.M. Hlavin, Factors predicting compliance with palivizumab in high-risk infants, Am J Perinatol. 18(6) (2001) 345-52.

[187] M.P. Frogel, D.L. Stewart, M. Hoopes, A.W. Fernandes, P.J. Mahadevia, A systematic review of compliance with palivizumab administration for RSV immunoprophylaxis, J Manag Care Pharm. 16(1) (2010) 46-58.

[188] Y.J. Son, H.G. Kim, E.H. Kim, S. Choi, S.K. Lee, Application of support vector machine for prediction of medication adherence in heart failure patients, Healthc Inform Res. 16(4) (2010) 253-9.

[189] J.A. Mullins, A.C. Lamonte, J.S. Bresee, L.J. Anderson, Substantial variability in community respiratory syncytial virus season timing, Pediatr Infect Dis J. 22(10) (2003) 857-62.

[190] C.A. Panozzo, A.L. Fowlkes, L.J. Anderson, Variation in timing of respiratory syncytial virus outbreaks: lessons from national surveillance, Pediatr Infect Dis J. 26(11 Suppl) (2007) S41-5.

[191] D. Hervás, J. Reina, J.A. Hervás, Meteorologic conditions and respiratory syncytial virus activity, Pediatr Infect Dis J. 31(10) (2012) e176-81. 
[192] N.L. Goddard, M.C. Cooke, R.K. Gupta, J.S. Nguyen-Van-Tam, Timing of monoclonal antibody for seasonal RSV prophylaxis in the United Kingdom, Epidemiol Infect. 135(1) (2007) 159-62.

[193] S. Vandini, L. Corvaglia, R. Alessandroni, G. Aquilano, C. Marsico, M. Spinelli, et al., Respiratory syncytial virus infection in infants and correlation with meteorological factors and air pollutants, Ital J Pediatr. 39(1) (2013) 1.

[194] J.B. du Prel, W. Puppe, B. Gröndahl, M. Knuf, J.A. Weigl, F. Schaaff, et al., Are meteorological parameters associated with acute respiratory tract infections? Clin Infect Dis. 49(6) (2009) 861-8.

[195] P. Zachariah, S. Shah, D. Gao, E.A. Simões, Predictors of the duration of the respiratory syncytial virus season, Pediatr Infect Dis J. 28(9) (2009) 772-6.

[196] E. Piippo-Savolainen, M. Korppi, Wheezy babies-wheezy adults? Review on long-term outcome until adulthood after early childhood wheezing, Acta Paediatr. 97(1) (2008) 5-11.

[197] M. Hyvärinen, E. Piippo-Savolainen, K. Korhonen, M. Korppi, Teenage asthma after severe infantile bronchiolitis or pneumonia, Acta Paediatr. 94(10) (2005) 1378-83.

[198] V. Larouch, G. Rivard, F. Deschesnes, R. Goulet, H. Turcotte, L.P. Boulet, Asthma and airway hyper-responsiveness in adults who required hospital admission for bronchiolitis in early childhood, Respir Med. 94(3) (2000) 288-94.

[199] K.M. McConnochie, K.J. Roghmann, Bronchiolitis as a possible cause of wheezing in childhood: new evidence, Pediatrics. 74(1) (1984) 1-10.

[200] E. Piippo-Savolainen, S. Remes, S. Kannisto, K. Korhonen, M. Korppi, Asthma and lung function 20 years after wheezing in infancy: results from a prospective follow-up study, Arch Pediatr Adolesc Med. 158(11) (2004) 1070-6.

[201] N. Sigurs, R. Bjarnason, F. Sigurbergsson, B. Kjellman, Respiratory syncytial virus bronchiolitis in infancy is an important risk factor for asthma and allergy at age 7, Am J Respir Crit Care Med. 161(5) (2000) 1501-7.

[202] A.M. Singh, P.E. Moore, J.E. Gern, R.F. Jr Lemanske, T.V. Hartert, Bronchiolitis to asthma: a review and call for studies of gene-virus interactions in asthma causation, Am J Respir Crit Care Med. 175(2) (2007) 108-19.

[203] M. Ruotsalainen, E. Piippo-Savolainen, M.K. Hyvärinen, M. Korppi, Adulthood asthma after wheezing in infancy: a questionnaire study at 27 years of age, Allergy. 65(4) (2010) 503-9.

[204] E. Khaldi, M. Joulak, F. Jawahdou, Infant asthma in Tunisia, Pediatr Pulmonol Suppl. 18 (1999) 216-9.

[205] I.B. Mikalsen, T. Halvorsen, G.E. Eide, K. Øymar, Severe bronchiolitis in infancy: can asthma in adolescence be predicted? Pediatr Pulmonol. 48(6) (2013) 538-44.

[206] U. Frey, E. von Mutius, The challenge of managing wheezing in infants, N Engl J Med. 360(20) (2009) 2130-3. 
[207] J.M. Mansbach, C.A. Jr. Camargo, Respiratory viruses in bronchiolitis and their link to recurrent wheezing and asthma, Clin Lab Med. 29(4) (2009) 741-55.

[208] M. Shinohara, H. Wakiguchi, H. Saito, K. Matsumoto, Presence of eosinophils in nasal secretion during acute respiratory tract infection in young children predicts subsequent wheezing within two months, Allergol Int. 57(4) (2008) 359-65.

[209] L. Bont, C.J. Heijnen, A. Kavelaars, W.M. van Aalderen, F. Brus, J.T. Draaisma, et al., Monocyte IL-10 production during respiratory syncytial virus bronchiolitis is associated with recurrent wheezing in a one-year follow-up study, Am $J$ Respir Crit Care Med. 161(5) (2000) 1518-23.

[210] L. Bont, W.M. Van Aalderen, J. Versteegh, F. Brus, J.T. Draaisma, M. Pekelharing-Berghuis, et al., Airflow limitation during respiratory syncytial virus lower respiratory tract infection predicts recurrent wheezing, Pediatr Infect Dis J. 20(3) (2001) 277-82.

[211] H.L. Chung, S.G. Kim, RANTES may be predictive of later recurrent wheezing after respiratory syncytial virus bronchiolitis in infants, Ann Allergy Asthma Immunol. 88(5) (2002) 463-7.

[212] A. Kotaniemi-Syrjänen, T.M. Reijonen, K. Korhonen, M. Korppi, Wheezing requiring hospitalization in early childhood: predictive factors for asthma in a six-year follow-up, Pediatr Allergy Immunol. 13(6) (2002) 418-25.

[213] M. Pifferi, V. Ragazzo, D. Caramella, G. Baldini, Eosinophil cationic protein in infants with respiratory syncytial virus bronchiolitis: predictive value for subsequent development of persistent wheezing, Pediatr Pulmonol. 31(6) (2001) 41924.

[214] E. Piippo-Savolainen, S. Remes, S. Kannisto, K. Korhonen, M. Korppi, Early predictors for adult asthma and lung function abnormalities in infants hospitalized for bronchiolitis: a prospective 18- to 20-year follow-up, Allergy Asthma Proc. 27(4) (2006) 341-9.

[215] E. Piippo-Savolainen, S. Remes, M. Korppi, Does early exposure or sensitization to inhalant allergens predict asthma in wheezing infants? A 20-year follow-up, Allergy Asthma Proc. 28(4) (2007) 454-61.

[216] E. Piippo-Savolainen, S. Remes, M. Korppi, Does blood eosinophilia in wheezing infants predict later asthma? A prospective 18-20-year follow-up, Allergy Asthma Proc. 28(2) (2007) 163-9.

[217] T.M. Reijonen, M. Korppi, L. Kuikka, K. Savolainen, M. Kleemola, I. Mononen, et al., Serum eosinophil cationic protein as a predictor of wheezing after bronchiolitis, Pediatr Pulmonol. 23(6) (1997) 397-403. 
[218] R. Soferman, D. Bar-Zohar, U. Jurgenson, E. Fireman, Soluble CD14 as a predictor of subsequent development of recurrent wheezing in hospitalized young children with respiratory syncytial virus-induced bronchiolitis, Ann Allergy Asthma Immunol. 92(5) (2004) 545-8.

[219] A. Schuurhof, R. Janssen, H. de Groot, H.M. Hodemaekers, A. de Klerk, J.L. Kimpen, et al., Local interleukin-10 production during respiratory syncytial virus bronchiolitis is associated with post-bronchiolitis wheeze, Respir Res. 12 (2011) 121.

[220] R.C. Welliver, M. Sun, D. Rinaldo, P.L. Ogra, Predictive value of respiratory syncytial virus-specific IgE responses for recurrent wheezing following bronchiolitis, J Pediatr. 109(5) (1986) 776-80.

[221] Y. Yamada, S. Yoshihara, Creola bodies in infancy with respiratory syncytial virus bronchiolitis predict the development of asthma, Allergol Int. 59(4) (2010) 375-80.

[222] M. Ruotsalainen, M.K. Hyvärinen, E. Piippo-Savolainen, M. Korppi, Adolescent asthma after rhinovirus and respiratory syncytial virus bronchiolitis, Pediatr Pulmonol. 48(7) (2013) 633-9.

[223] D.R. Ehlenfield, K. Cameron, R.C. Welliver, Eosinophilia at the time of respiratory syncytial virus bronchiolitis predicts childhood reactive airway disease, Pediatrics. 105(1 Pt 1) (2000) 79-83.

[224] D.C. Cassimos, A. Tsalkidis, G.A. Tripsianis, A. Stogiannidou, M. Anthracopoulos, S. Ktenidou-Kartali, et al., Asthma, lung function and sensitization in school children with a history of bronchiolitis, Pediatr Int. 50(1) (2008) 51-6.

[225] L.B. Bacharier, R. Cohen, T. Schweiger, H. Yin-Declue, C. Christie, J. Zheng, et al., Determinants of asthma after severe respiratory syncytial virus bronchiolitis, J Allergy Clin Immunol. 130(1) (2012) 91-100.

[226] A. Beigelman, L.B. Bacharier, The role of early life viral bronchiolitis in the inception of asthma, Curr Opin Allergy Clin Immunol. 13(2) (2013) 211-6.

[227] G.J. Escobar, A. Ragins, S.X. Li, L. Prager, A.S. Masaquel, P. Kipnis, Recurrent wheezing in the third year of life among children born at 32 weeks' gestation or later: relationship to laboratory-confirmed, medically attended infection with respiratory syncytial virus during the first year of life, Arch Pediatr Adolesc Med. 164(10) (2010) 915-22.

[228] L. Kuikka, T. Reijonen, K. Remes, M. Korppi, Bronchial asthma after early childhood wheezing: a follow-up until 4.56 years of age, Acta Paediatr. 83(7) (1994) 744-8.

[229] F. Midulla, A. Pierangeli, G. Cangiano, E. Bonci, S. Salvadei, C. Scagnolari, et al., Rhinovirus bronchiolitis and recurrent wheezing: 1-year follow-up, Eur Respir J. 39(2) (2012) 396-402. 
[230] K. Nuolivirta, P. Koponen, M. Helminen, M. Korppi, Weight gain in infancy and post-bronchiolitis wheezing, Acta Paediatr. 101(1) (2012) 38-42.

[231] P. Koponen, M. Helminen, M. Paassilta, T. Luukkaala, M. Korppi, Preschool asthma after bronchiolitis in infancy, Eur Respir J. 39(1) (2012) 76-80.

[232] C.K. Kim, J.K. Seo, S.H. Ban, T. Fujisawa, D.W. Kim, Z. Callaway, Eosinophil-derived neurotoxin levels at 3 months post-respiratory syncytial virus bronchiolitis are a predictive biomarker of recurrent wheezing, Biomarkers. 18(3) (2013) $230-5$.

[233] H. Valkonen, M. Waris, A. Ruohola, O. Ruuskanen, T. Heikkinen, Recurrent wheezing after respiratory syncytial virus or non-respiratory syncytial virus bronchiolitis in infancy: a 3-year follow-up, Allergy. 64(9) (2009) 1359-65.

[234] J.A. Castro-Rodríguez, C.J. Holberg, A.L. Wright, F.D. Martinez, A clinical index to define risk of asthma in young children with recurrent wheezing, Am J Respir Crit Care Med. 162(4 Pt 1) (2000) 1403-6.

[235] J.F. Oliveti, C.M. Kercsmar, S. Redline, Pre- and perinatal risk factors for asthma in inner city African-American children, Am J Epidemiol. 143(6) (1996) 570-7.

[236] L.K. Arruda, D. Solé, C.E. Baena-Cagnani, C.K. Naspitz, Risk factors for asthma and atopy, Curr Opin Allergy Clin Immunol. 5(2) (2005) 153-9.

[237] C.B. Sherman, T.D. Tosteson, I.B. Tager, F.E. Speizer, S.T. Weiss, Early childhood predictors of asthma, Am J Epidemiol. 132(1) (1990) 83-95.

[238] C. Voisin, A. Sardella, F. Marcucci, A. Bernard, Infant swimming in chlorinated pools and the risks of bronchiolitis, asthma and allergy, Eur Respir J. 36(1) (2010) 41-7.

[239] K.A. Karunasekera, J.A. Jayasinghe, L.W. Alwis, Risk factors of childhood asthma: a Sri Lankan study, J Trop Pediatr. 47(3) (2001) 142-5.

[240] M. Korppi, Asthma predictive factors in infants with bronchiolitis: asthma risk at 13-20 years of age, Eur Respir J. 36(1) (2010) 221-2.

[241] J.M. Mansbach, C.A. Camargo, Update on bronchiolitis, Emerg Med Crit Rev. 4 (2008) 35-8.

[242] M. Howidi, J. Rajah, Z. Abushrar, H. Parsons, The severity of respiratory syncytial virus bronchiolitis in young infants in the United Arab Emirates, J Trop Pediatr. 53(1) (2007) 22-6.

[243] M. Koehoorn, C.J. Karr, P.A. Demers, C. Lencar, L. Tamburic, M. Brauer, Descriptive epidemiological features of bronchiolitis in a population-based cohort, Pediatrics. 122(6) (2008) 1196-203. 
[244] K. Rakshi, J.M. Couriel, Management of acute bronchiolitis, Arch Dis Child. 71(5) (1994) 463-469.

[245] S. Ricart, M.A. Marcos, M. Sarda, A. Anton, C. Muñoz-Almagro, T. Pumarola, et al., Clinical risk factors are more relevant than respiratory viruses in predicting bronchiolitis severity, Pediatr Pulmonol. 48(5) (2013) 456-63.

[246] R.A. Martinello, M.D. Chen, C. Weibel, J.S. Kahn, Correlation between respiratory syncytial virus genotype and severity of illness, J Infect Dis. 186(6) (2002) 839-42.

[247] E.E. Walsh, K.M. McConnochie, C.E. Long, C.B. Hall, Severity of respiratory syncytial virus infection is related to virus strain, J Infect Dis. 175(4) (1997) 814-20.

[248] R.A. Vieira, E.M. Diniz, M.E. Ceccon, Correlation between inflammatory mediators in the nasopharyngeal secretion and in the serum of children with lower respiratory tract infection caused by respiratory syncytial virus and disease severity, $J$ Bras Pneumol. 36(1) (2010) 59-66.

[249] M.G. Semple, H.M. Dankert, B. Ebrahimi, J.B. Correia, J.A. Booth, J.P. Stewart, et al., Severe respiratory syncytial virus bronchiolitis in infants is associated with reduced airway interferon gamma and substance P, PLoS One. 2(10) (2007) e1038.

[250] P. Papoff, C. Moretti, G. Cangiano, E. Bonci, M. Roggini, A. Pierangeli, et al., Incidence and predisposing factors for severe disease in previously healthy term infants experiencing their first episode of bronchiolitis, Acta Paediatr. 100(7) (2011) e17-23.

[251] V.J. Flaherman, A.I. Ragins, S.X. Li, P. Kipnis, A. Masaquel, G.J. Escobar, Frequency, duration and predictors of bronchiolitis episodes of care among infants $\geq 32$ weeks gestation in a large integrated healthcare system: a retrospective cohort study, BMC Health Serv Res. 12 (2012) 144.

[252] E.E. Wang, B.J. Law, D. Stephens, Pediatric Investigators Collaborative Network on Infections in Canada (PICNIC) prospective study of risk factors and outcomes in patients hospitalized with respiratory syncytial viral lower respiratory tract infection, J Pediatr. 126(2) (1995) 212-9.

[253] N. Akiyama, T. Segawa, H. Ida, H. Mezawa, M. Noya, S. Tamez, et al., Bimodal effects of obesity ratio on disease duration of respiratory syncytial virus infection in children, Allergol Int. 60(3) (2011) 305-8.

[254] R.C. Tasker, I. Gordon, K. Kiff, Time course of severe respiratory syncytial virus infection in mechanically ventilated infants, Acta Paediatr. 89(8) (2000) 938-41.

[255] M.C. Spaeder, J.C. Fackler, Time series model to predict burden of viral respiratory illness on a pediatric intensive care unit, Med Decis Making. 31(3) (2011) 494-9. 
[256] M.L. Houben, M.M. Rovers, B. Wilbrink, M.E. Belderbos, E.M. Bloemen-Carlier, G.H. Visser, et al., High concentrations of amniotic fluid proinflammatory cytokines in healthy neonates are associated with low risk of respiratory syncytial virus bronchiolitis, Pediatr Infect Dis J. 31(9) (2012) 931-4.

[257] G. Luo, A roadmap for designing a personalized search tool for individual healthcare providers, J Med Syst. 38(2) (2014) 6.

[258] S.L. Morgan, C. Winship, Counterfactuals and Causal Inference: Methods and Principles for Social Research, Cambridge University Press, New York, NY, 2007.

[259] J. Pearl, Causality: Models, Reasoning, and Inference, 2nd Ed., Cambridge University Press, New York, NY, 2009.

[260] M. Markatou, P.K. Don, J. Hu, F. Wang, J. Sun, R. Sorrentino, et al., Case-based reasoning in comparative effectiveness research, IBM Journal of Research and Development 56(5) (2012) 4.

[261] G. Luo, Open issues in intelligent personal health record - an updated status report for 2012, J Med Syst. 37(3) (2013) 9943.

[262] M. Conway, J.N. Dowling, W.W. Chapman, Using chief complaints for syndromic surveillance: a review of chief complaint based classifiers in North America, J Biomed Inform. 46(4) (2013) 734-43.

[263] I. Guyon, A. Elisseeff, An introduction to variable and feature selection, Journal of Machine Learning Research 3 (2003) $1157-1182$.

[264] H. Neuvirth, M. Ozery-Flato, J. Hu, J. Laserson, M.S. Kohn, S. Ebadollahi, et al., Toward personalized care management of patients at risk: the diabetes case study, in: Proceedings of KDD’11, 2011, pp. 395-403.

[265] J. Jiang, A literature survey on domain adaptation of statistical classifiers, available at http://sifaka.cs.uiuc.edu/jiang4/domain_adaptation/survey/da_survey.pdf, 2008.

[266] J.E. Wennberg, Dealing with medical practice variations: a proposal for action, Health Aff (Millwood). 3(2) (1984) 6-32.

[267] Health Services Research Group, Small area variations: What are they and what do they mean? Can Med Assoc J 146(4) (1992) 467-470.

[268] J.E. Wennberg, Which rate is right? N Eng J Med. 314(5) (1986) 310-311.

[269] J. Wiens, J. Guttag, E. Horvitz, A study in transfer learning: leveraging data from multiple hospitals to enhance hospitalspecific predictions, J Am Med Inform Assoc. (2014) doi: 10.1136/amiajnl-2013-002162.

[270] S.J. Pan, Q. Yang, A survey on transfer learning, IEEE Trans. Knowl. Data Eng. 22(10) (2010) 1345-1359. 
[271] A. Johnson, C. Hartling, C.J. Hoydu, J. Ballard, Adventure in bronchiolitis: respiratory outpatient clinic education \& review, NACHRI 2009 Annual Meeting poster presentation, available at http://www.childrenshospitals.net/AM/Template.cfm?Section=t\&template=/CM/ContentDisplay.cfm\&ContentID=48598.

[272] D. Moher, A. Liberati, J. Tetzlaff, D.G. Altman, The PRISMA Group, Preferred Reporting Items for Systematic Reviews and Meta-Analyses: the PRISMA statement, PLoS Med. 6(7) (2009) e1000097.

[273] K. Bonnie, Evaluating informatics applications - clinical decision support systems literature review, Int J Med Inform. $2001 ; 64(1): 15-37$.

\section{Appendix: List of acronyms}

$\begin{array}{ll}\text { AUC } & \text { area under the receiver operating characteristic curve } \\ \text { BiPAP } & \text { bilevel positive airway pressure } \\ \text { CART } & \text { Classification And Regression Tree } \\ \text { CPAP } & \text { emergency department } \\ \text { ED } & \text { high-flow nasal cannula } \\ \text { HFNC } & \text { intensive care unit } \\ \text { ICU } & \text { non-invasive positive pressure ventilation } \\ \text { NIPPV } & \text { polymerase chain reaction } \\ \text { PCR } & \text { respiratory syncytial virus }\end{array}$

